\title{
LAS MONEDAS DE LOS CAMPAMENTOS ROMANOS DE CAMPAÑA DE LAS GUERRAS CÁNTABRAS DEL ASEDIO DE LA LOMA, CASTILLEJO Y EL ALAMBRE
}

\author{
COINS FROM THE ROMAN CAMPAIGN CAMPS OF THE CANTABRIAN WARS OF THE SIEGE OF LA LOMA, \\ CASTILLEJO AND EL ALAMBRE
}

\author{
EDUARDO PERALTA LABRADOR \\ JOSÉ ÁNGEL HIERRO GÁRATE \\ ENRIQUE GUTIÉRREZ CUENCA
}

\section{INTRODUCCIÓN}

Gracias a las prospecciones y excavaciones arqueológicas llevadas a cabo desde el año 1996 en las áreas de montaña del sector central de Cantabria, trabajos que continuamos hasta el año 2007 en el norte de Burgos y Palencia dentro del «Proyecto Guerras Cántabras», actualmente se conoce ya un buen número de campamentos romanos de campaña (castra aestiva) y de oppida indígenas atacados o asediados durante las Guerras Cántabras ${ }^{1}$. A nuestros descubrimientos se han añadido en los últimos años las importantes aportaciones de otros investigadores en la misma Cantabria, en Asturias y en el norte de Castilla ${ }^{2}$.

Estas evidencias arqueológicas nos han permitido esclarecer en buena medida cuáles fueron algunos de los principales teatros de operaciones de las Guerras Cántabras y comprender el desarrollo de las mismas y el modus operandi del ejército romano de conquista: una primera fase de sometimiento de los grandes

\footnotetext{
1. La bibliografía generada por estas investigaciones es amplia. Sobre las evidencias de Cantabria (Cildá, Espina del Gállego, El Cantón, Campo de las Cercas, etc.): Peralta, 1997; 1998; 1999a;, 1999b; 2000; 2001a; 2001b, 178 ss.; 2002b; 2002c; 2003, 273 ss., 308 ss.; 2004a, 117 ss.; 2009a, 261 ss.; 2011; Peralta, Fernández y Ayllón, 2000; Peralta, Sáez y Fernández, 2010. Sobre las evidencias de Burgos y Palencia (La Muela, Castillejo, La Loma, etc.): Peralta, 2001b; 2002b; 2003, 301 ss.; 2004a, 112 ss; 2004b; 2006a; 2006b; 2007; $2009 \mathrm{~b}$.

2. Recogemos aquí las aportaciones más importantes en los diferentes territorios. Sobre estas nuevas evidencias de las Guerras Cántabras en Cantabria: Fernández y Bolado, 2010 (Santa Marina), Cepeda, 2006a; 2006b; 2007; 2008 (La Poza), Bolado y Fernández, 2010b (El Pedrón), Hierro, 2010 (Salces), García Alonso, 2002; 2003; 2006; 2007 (El Cincho). Sobre Asturias: Camino, Viniegra y Estrada, 2005; Camino, Estrada y Viniegra, 2006; González, Menéndez y Álvarez, 2008. Sobre las evidencias de Burgos y Palencia: Fraile, 2006. Sobre la evidencias de Álava: Ocharan y Unzueta, 2002; Unzueta y Ocharan, 1999.
}

oppida meridionales (La Loma, El Bernorio...) y una segunda fase de avance hacia los puertos de la costa por los cordales montañosos de la vertiente septentrional (Interfluvio Pas-Besaya en Cantabria y La Carisa en Asturias).

Por lo que respecta a las estructuras militares romanas localizadas, se trata en su totalidad de campamentos de campaña (castra aestiva) como los descritos por Polibio, César, Tito Livio, Flavio Josefo, el PseudoHyginio o $\mathrm{Vegecio}^{3}$, que, según exigía la disciplina militar romana, se levantaban todos los días después de una jornada de marcha para que el ejército pernoctase en tiendas de campaña protegido por las fortificaciones, o bien cumplían la función de bases semiestables mientras las operaciones en la zona así lo impusiesen. Este tipo de construcciones temporales, diferentes de los campamentos estables (castra stativa y castra hiberna), fueron un factor decisivo en el éxito del ejército romano y sus restos nos informan con exactitud sobre el territorio donde operaron las tropas de Roma durante las campañas militares de las que hablan las fuentes (Peralta, 2002a; 2009b, 276 ss.).

En este tipo de establecimientos temporales, aparte de algunos modelos de fíbulas de cronología augustea o anteriores, los materiales arqueológicos que nos aportan unas mayores precisiones para la correcta interpretación de los yacimientos y de sus cronologías dentro de las diversas fases del Bellum Cantabricum, son los materiales numismáticos. Aquí nos proponemos tratar sobre los procedentes de nuestros trabajos arqueológicos en el asedio de La Loma y en los campamentos romanos de Castillejo y El Alambre, situados en las inmediaciones del castro de Monte Bernorio (Fig. 1).

3. Polibio, VI, 27-42. César, Corpus Caesarianum. Livio, XLIV, 39, 2-5. Flavio Josefo, Bello Iudaico, III, 77-92. Pseudo-Hyginio, De munitionibus castrorum. Vegecio, Epitomae rei militaris, I, 21-25; III, 8. 


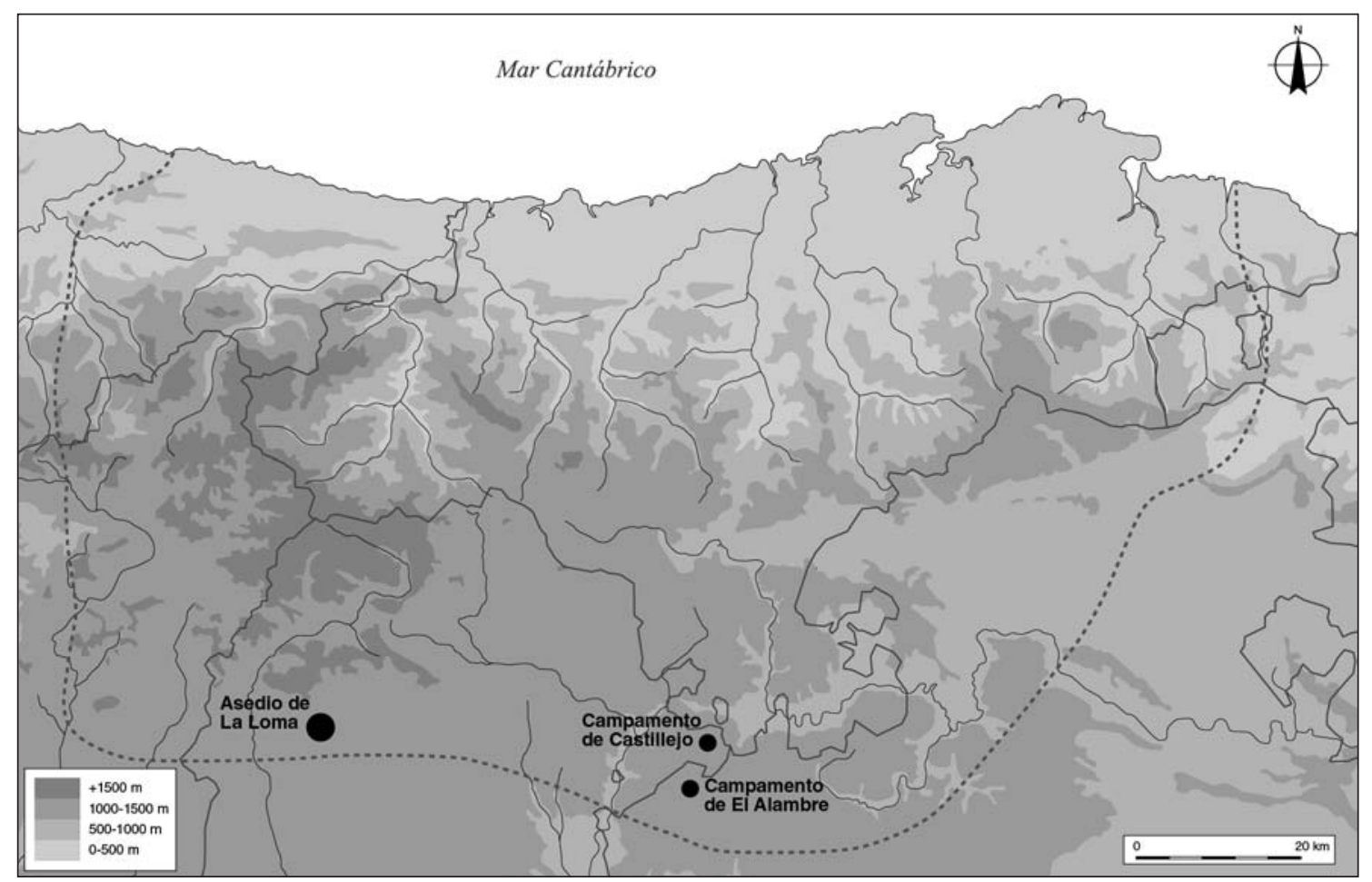

Figura 1: Situación de los yacimientos en la antigua Cantabria.

\section{ASEDIO DE LA LOMA}

Los altos de La Loma se encuentran en la comarca del Alto Carrión, al pie de la Sierra del Brezo, junto a Santibáñez de la Peña (Palencia). En ellos son visibles los restos de las fortificaciones de asedio del ejército romano a un importante oppidum cántabro. El centro de este complejo arqueológico lo constituye el asentamiento cántabro, alrededor del cual existe un clásico dispositivo de asedio romano constituido por un campamento principal, posiblemente el campamento de una legión o de parte de una, y varios campamentos menores o fortines (castella) unidos por restos de una circunvalación y de una contravalación. En estos enclaves se intervino arqueológicamente entre los años 2003 y 2007 (Peralta, 2003, 303 ss.; 2004b; Peralta, 2006b; 2007; 2008; 2009a:,256 ss.).

\subsection{LOS YACIMIENTOS}

\section{Oppidum de El Castro}

Coordenadas UTM: X: 358062 Y: 4739830.

Lugar: El Castro.

Localidad: Santibáñez de la Peña.

Municipio: Santibáñez de la Peña (Palencia).

El centro del yacimiento y el punto más alto del mismo es la cota 1124 del mapa 132-I del Instituto Geográfico Nacional. Está emplazado en una loma parcialmente acantilada por el oeste y por el sur, controlando el estrechamiento de $\mathrm{La} \mathrm{Hoz}$, donde se unen los ríos
Valdavia y Las Heras y el arroyo de San Román. Es un castro de gran entidad que ocupa una superficie habitable de 10'18 ha. En su punto más accesible del sector nordeste y norte dispone de un potente derrumbe de muralla con foso exterior. En el interior existe otro amurallamiento que con la muralla exterior forma un primer recinto de 2'7 ha. El resto del asentamiento está protegido por cantiles (Fig. 2).

La muralla alcanza su mayor envergadura en el ángulo situado frente al campamento romano principal, donde las potentes obras defensivas intentaron suplir las deficiencias del terreno. El derrumbe actual por la cara externa alcanza más de doce metros de altura desde la cima a la base del terraplén. Esta defensa se completaba con un foso exterior en $\mathrm{V}$ de $4 \mathrm{~m}$ de anchura

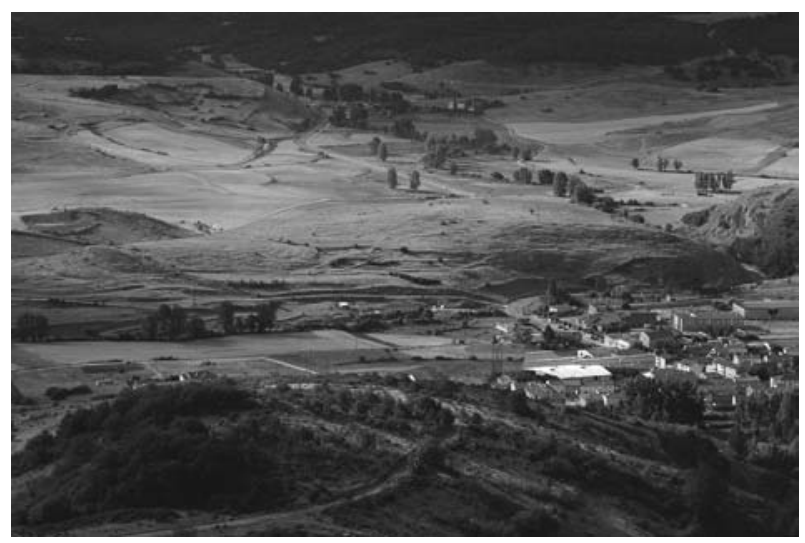

Figura 2: Vista aérea de El Castro, oppidum del asedio de La Loma. 


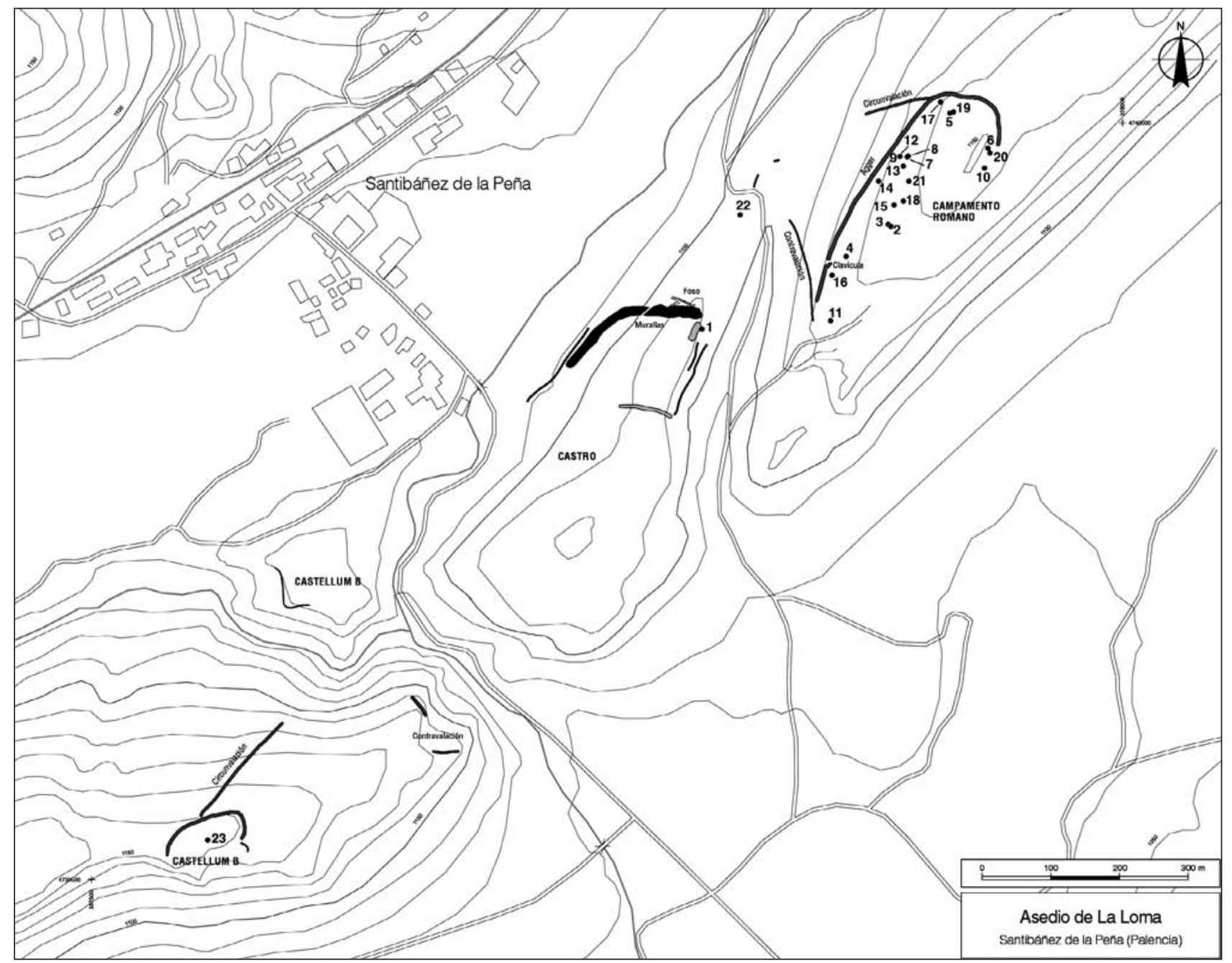

Figura 3: Plano de distribución de los hallazgos numismáticos en el asedio de La Loma.

por otros tantos de profundidad, que fue tallado en el subsuelo rocoso aprovechando una grieta natural. En la ladera sur del castro, cerca de las anteriores estructuras, existe además un gran bastión adosado a la cara externa de la muralla y otros complejos refuerzos en los amurallamientos.

Se ha documentado que el ejército romano expugnó la plaza mediante un asalto (oppugnatio). Este asalto se produjo en la esquina en ángulo de las murallas situada frente al campamento romano principal. En este punto, tanto en la cara exterior de la muralla como en el foso, se han encontrado numerosísimas puntas de flecha romanas y algunos pila catapultaria y proyectiles de ballista arrojados durante el asalto a las murallas. La cara exterior de la muralla fue destruida y hay un potente nivel de incendio tanto en el talud de ésta como en el foso. En el interior del castro se han documentado igualmente niveles de destrucción e incendio asociados a algunos restos humanos, así como el arrasamiento intencional hasta los cimientos de un sector de la muralla asaltada para hacer inservible el recinto defensivo.
Los materiales arqueológicos procedentes del oppidum son especialmente abundantes. Algunos son de la I Edad del Hierro, pero la mayoría se sitúan entre los siglos III-I a. de C. o corresponden ya a la intervención militar romana. La única moneda encontrada en el castro es un denario de Turiaso aparecido en la esquina noroeste (Fig. 3).

\section{Campamento romano de La Loma}

Coordenadas UTM: X: 358568 Y: 4740275.

Lugar: La Loma.

Localidad: Santibáñez de la Peña.

Municipio: Santibáñez de la Peña (Palencia).

Está situado al sur de Santibáñez de la Peña y al sudeste de Las Heras de la Peña, sobre una eminencia alargada bordeada por el arroyo de San Román por el norte y la localidad de Pino de Viduerna por el sur. Tiene 5'9 ha y es visible gran parte de su perímetro defensivo, formado por un agger o aterrazamiento de tierra y piedra en el que se abre una puerta en clavicula interna, elemento determinante para considerarlo con 


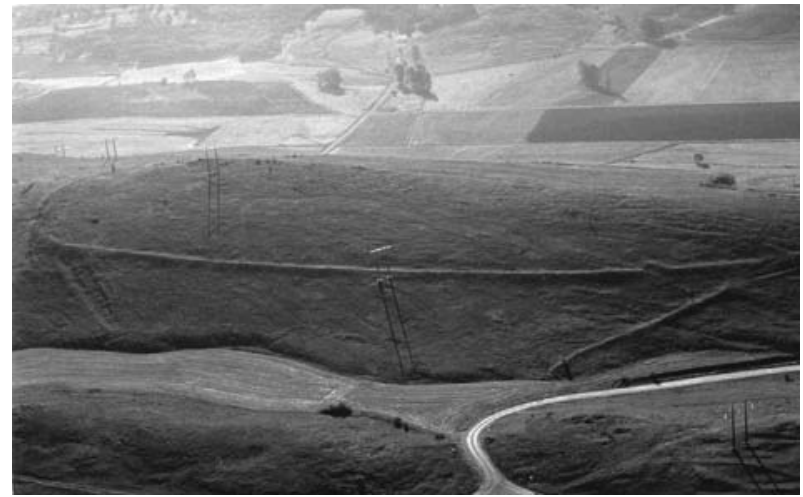

Figura 4; Vista aérea del campamento romano de campaña del asedio de La Loma, con el arranque de las líneas de circunvalación y contravalación.

seguridad un campamento romano de campaña (castra aestiva). Su planta tiene forma alargada con ángulos redondeados, para adaptarse a las características topográficas del lugar. Del sector noroeste salen, de ambas esquinas del campamento, dos atrincheramientos correspondientes a la contravalación para cercar al castro situado enfrente y a la circunvalación que protegía la retaguardia del ejército de asedio (Fig. 4).

El yacimiento ha suministrado abundante material militar romano del período augusteo. Los objetos recuperados en las excavaciones nos indican que corresponde a una campaña de primavera o verano del ejército romano, puesto que han aparecido numerosas clavijas de las tiendas de campaña y regatones de hierro de grandes dimensiones para postes de tienda, la mayoría hincados in situ dentro del recinto campamental. El equipamiento militar del campamento principal nos permite conocer que el contingente estaba integrado por legionarios, como lo atestigua la presencia de varias piezas de pilum y de colgantes de apron del cinturón legionario; por tropas de caballería, de las que se han conservado bocados de caballo, espuelas y colgantes de los atalajes de los caballos; por auxiliares de infantería pesada, como evidencian las puntas de lanza; y varias unidades de arqueros, a juzgar por las numerosas puntas de flecha. Las tropas emplearon también artillería, tal y como pone de manifiesto el hallazgo de varios pila catapultaria.

Junto al abundante equipamiento militar ha aparecido un interesante conjunto numismático formado por veinte piezas de plata y bronce, repartidas por todo el recinto (Fig. 3).

\section{Castellum B}

Coordenadas UTM: X: 357530 Y: 4739369.

Lugar: La Loma.

Localidad: Las Heras de la Peña.

Municipio: Santibáñez de la Peña (Palencia).

$\mathrm{Al}$ oeste de La Hoz, en la prolongación de La Loma cuya cima está ocupada por un repetidor de TV y por antenas de telefonía (cota 1240 del M.T.N. 132-I),

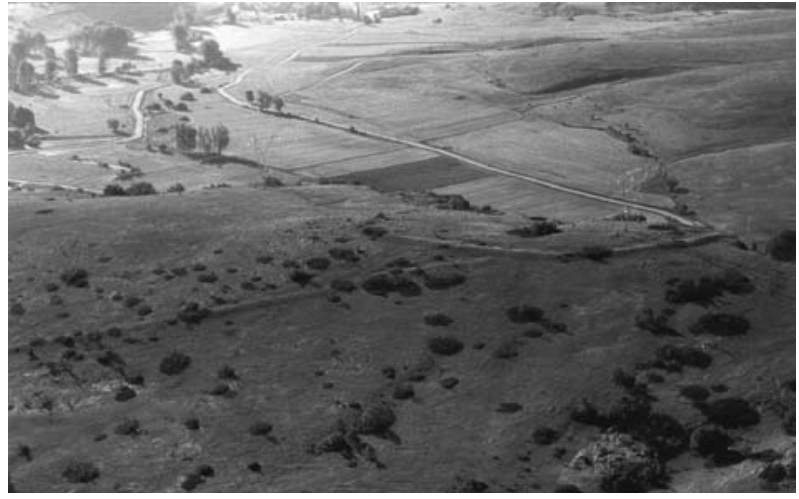

Figura 5: Vista aérea del castellum B del asedio de La Loma.

cruza hacia el este una línea de alta tensión. El yacimiento se encuentra donde está instalada la torre de alta tensión del punto más alto. Es un pequeño campamento o castellum de planta ovalada y con $6.517 \mathrm{~m}^{2}$ de superficie. Se aprecia perfectamente el derrumbe de piedra de su amurallamiento y un atrincheramiento de la circunvalación que sale del recinto defensivo y desciende hacia el río Las Heras para conectar, probablemente, con el castellum A (Fig. 5).

Desde la punta que domina el encajonamiento de La Hoz y la ladera oeste del castro asediado, desciende hacia el río por la ladera norte otro agger muy arrasado, resto de la contravalación del asedio. Quedan otros vestigios de esa contravalación en la ladera este, situada sobre el río y frente al castro.

El enclave ha suministrado diverso armamento y utillaje militar romano. Del centro del castellum ovalado procede un as de Calagurris (Fig. 3).

\subsection{LAS MONEDAS}

Las monedas recuperadas en los yacimientos que forman el asedio de La Loma suman un total de 23, repartidas de la siguiente manera: una en la fortaleza indígena de El Castro, 20 en el interior del campamento romano principal, otra en el espacio comprendido entre esos dos recintos y por el que tuvo lugar el asalto al oppidum cántabro, y una más en el castellum B.

Junto al castro (Fig. 6):

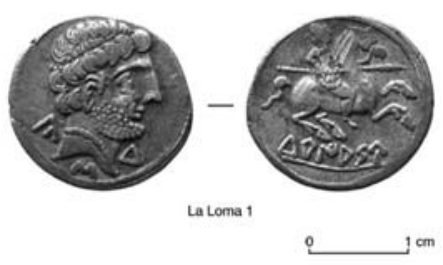

Figura 6: Denario de Turiaso encontrado en El Castro. 
1. TURIASO. Emisión de finales del siglo II a. de C. (alrededor de 120 a. de C.).

Ag. Denario. 18,65 mm. 3,20 g. Cuño 12 h.

Anv.: Cabeza barbada con torques a derecha, con leyenda ka (a la izquierda) s (debajo) tu (a la derecha).

Rev.: Jinete lancero a derecha y leyenda tu.r.i.a.s.u. sobre exergo.

Gozalbes 2009, V/56-610, DCPH 6. 2, CNH 266-267/33-34

Coordenadas: $358388-4740300$

En el campamento principal (Figs. 7, 8, 9 y 10):

2. ROMA (L. Titurius Sabinus). Emisión del año 89 a. de C.

Ag. Denario. 12 mm. 3,37 g. Cuño 6 h.

Anv.: Cabeza barbada del rey sabino Tito Tacio a derecha, con leyenda SABIN a la izquierda, junto a gráfila punteada y $[\underline{\mathrm{AT}}]$ a la derecha (no aparece en este ejemplar por el desplazamiento del cuño).

Rev.: escena con el rapto de las Sabinas y leyenda L TITVRI bajo exergo.

RRC 344/1 ${ }^{\mathrm{a}}$.

Coordenadas: 358662-4740450.

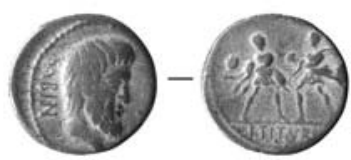

La Loma 2

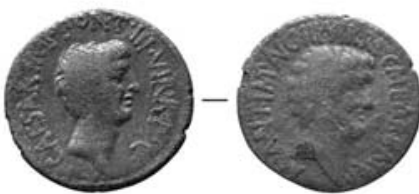

La Loma 3

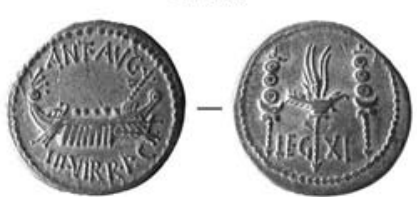

La Loma 4

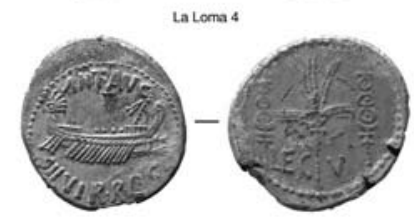

Latoma 5

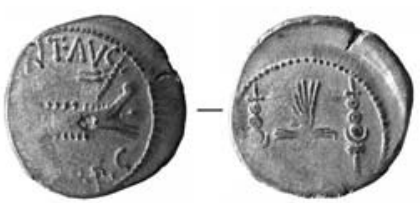

La Loma 6

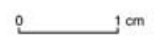

Figura 7: Denarios encontrados en el campamento de La Loma.
3. ÉFESO. Emisión del año 41 a. de C.

Ae/Ag. Denario forrado. 18,82mm. 2,40 g. Cuño $7 \mathrm{~h}$. Anv.: Cabeza de Octavio a derecha y leyenda CAESAR.IMP.PONT.III.VIR.R.P.C. alrededor.

Rev.: Cabeza de Marco Antonio a derecha y leyenda M ANT IMP AVG III VIR R P C M BARBAT Q P alrededor.

$R R C 517 / 2$.

Coordenadas: 358659-4740452.

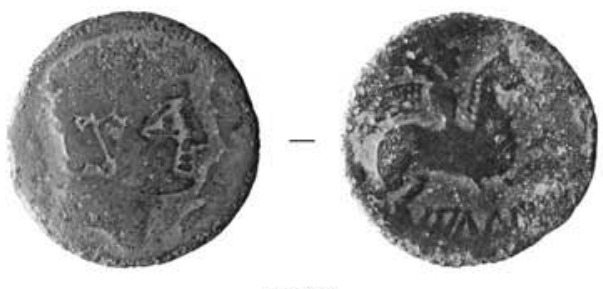

La Loma 7

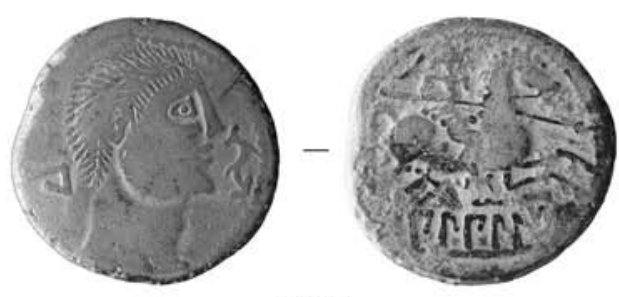

La Loma 8

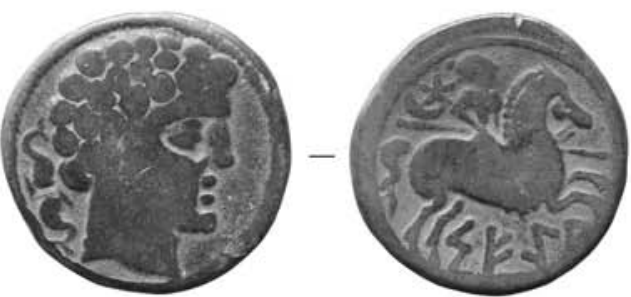

LaLoma9

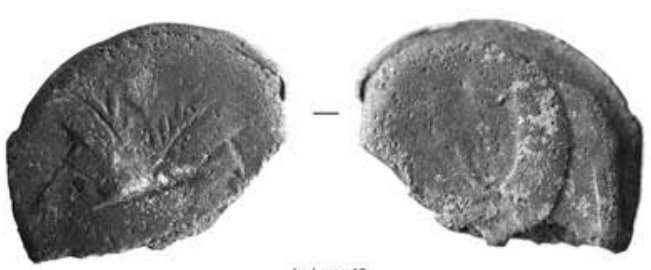

La Loma 10

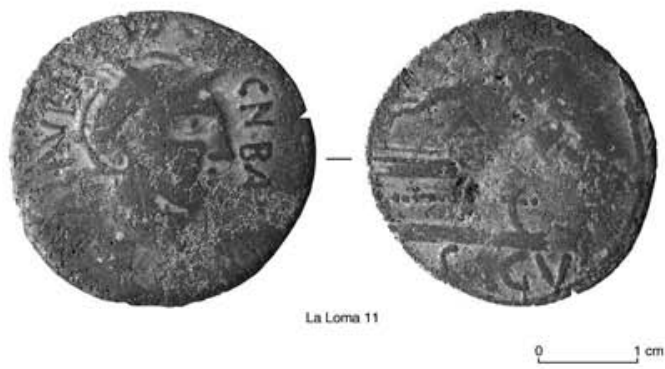

Figura 8; Ases de diversas procedencias encontrados en el campamento de La Loma. 


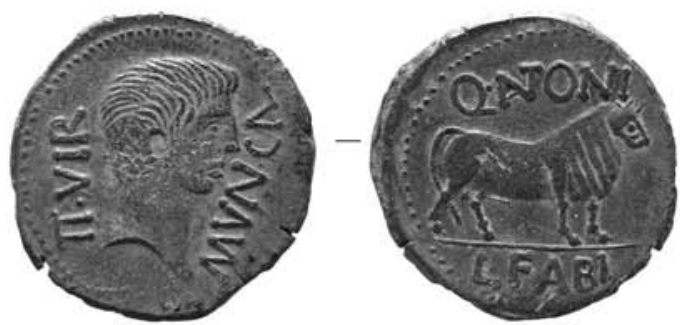

La Loma 12
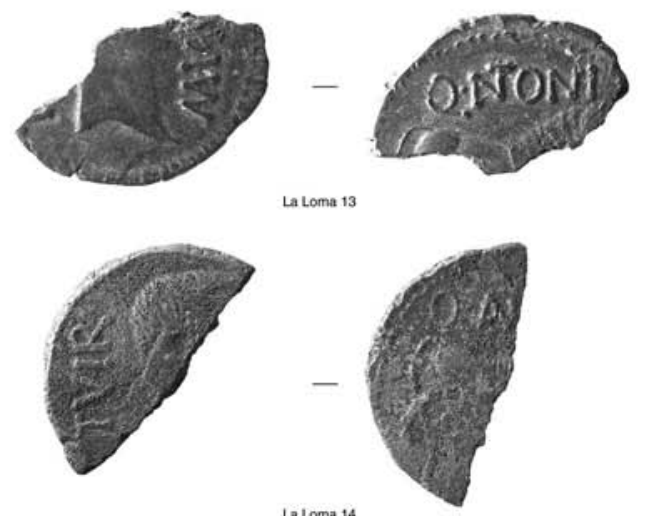

La Loma 14
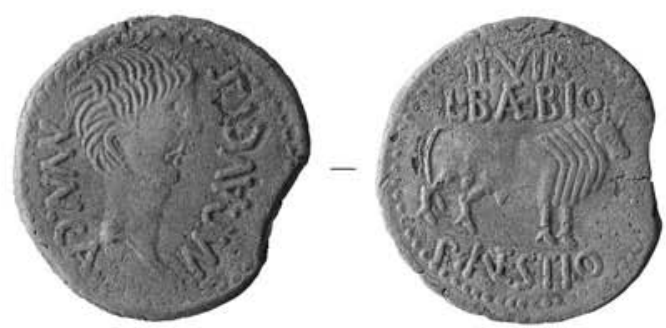

La Loma 15
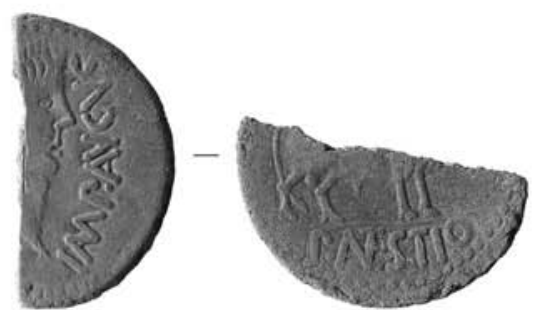

La Loma 16

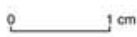

Figura 9: Ases de Calagurris encontrados en el campamento de La Loma.

4. CECA MÓVIL. Emisión de los años 32-31 a. de C. Ag. Denario. 17 mm. 3,57 g. Cuño 6 h.

Anv.: Galera a derecha con leyenda ANT.AVG (encima) III.VIR.R.P.C (debajo).

Rev.: Enseñas legionarias (águila entre dos signa) y leyenda LEG XI (debajo).

RRC 544/25.

Coordenadas: 358600-4740403.

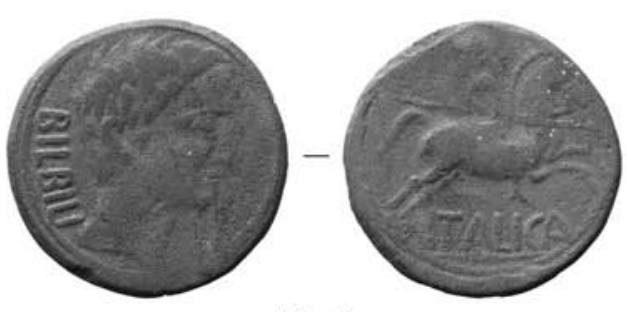

La Loma 17

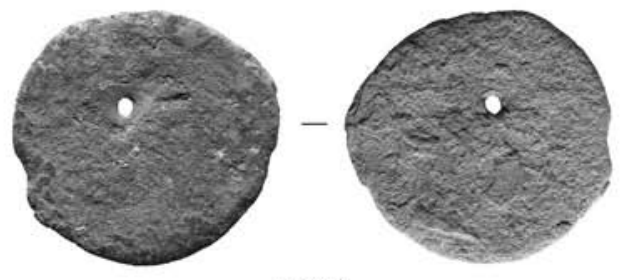

La Loma 18

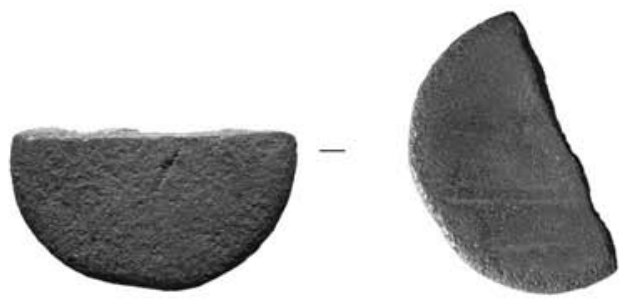

La Loma 19

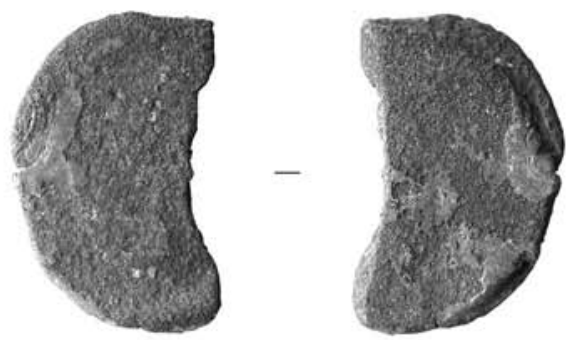

La Loma 20

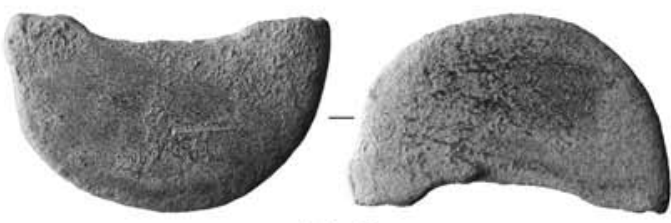

La Loma 21

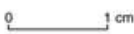

Figura 10: Ases de procedencias diversas encontrados en el campamento de La Loma.

5. CECA MÓVIL. Emisión de los años 32-31 a. de C. Ae/Ag. Denario forrado. 17,87 mm. 2,90 g. Cuño $11 \mathrm{~h}$. Anv.: Galera a derecha con leyenda ANT.AVG (encima) III.VIR.R.P.C (debajo).

Rev.: Enseñas legionarias (águila entre dos signa) y leyenda LEG V (debajo).

RRC 544/18.

Coordenadas: 358749-4740614. 
6. CECA MÓVIL. Emisión de los años 32-31 a. de C. Ae/Ag. Denario forrado. $17 \mathrm{~mm} .2,87 \mathrm{~g}$. Cuño $6 \mathrm{~h}$. Anv.: Galera a derecha con leyenda [A]NT.AVG (encima) [III.VIR.]R.P.C (debajo).

Rev.: Enseñas legionarias (águila entre dos signa) y leyenda [LEG..] (debajo).

RRC 544/?

Coordenadas: 358804-4740563.

7. SALTUIE. Emisión del tránsito entre los siglos II a. de C. y I a. de C.

Ae. As. 26 mm. 11,59 g. Cuño 5 h.

Anv.: Cabeza masculina a derecha, con 2 delfines delante y 1 detrás.

Rev: Jinete a la derecha, con casco, palma y clámide flotante, sobre exergo con leyenda s.a.l.tu.i.e.

DCPH 1, CNH 228/1.

Coordenadas: 358688-4740554.

8. BILBILIS. Emisión de entre mediados del siglo II a. de C. e inicios del siglo I a. de C.

Ae. As (Unidad en DCPH). 25 mm. 9,33 g. Cuño 10 h. Anv.: Cabeza masculina con collar a derecha, con delfín delante y leyenda bi (a la izquierda).

Rev.: Jinete lancero a derecha y leyenda bi.l.bi.l.i.s sobre exergo.

DCPH 6, CNH 239/11.

Coordenadas: 358689-4740555.

9. SEKIA. Emisión del tránsito entre los siglos II a. de C. y I a. de C.

Ae. As. (Unidad en DCPH). 28,23 mm. 12,90 g. Cuño $2 \mathrm{~h}$.

Anv.: Cabeza masculina a derecha y dos delfines enfrentados detrás.

Rev.: Jinete lancero a derecha, con estrella sobre creciente lunar encima y leyenda s.e.ki.a. sobre exergo.

DCPH 10, CNH 217/14.

Coordenadas: 358676-4740551.

10. ROMA. Emisión del siglo II a. de C.

Ae. As partido. ¿28? mm. 10,97 g. Cuño 6 h.

Anv.: Cabeza bifronte del dios Jano (parte superior)

Rev: Proa de galera (parte derecha)

Coordenadas: 358799-4740534

11. SAGUNTUM. Emisión entre los años 56-27 a.C. Ae. As. 30 mm. 8,00 g. Cuño. 5 h.

Anv.: Cabeza femenina galeada (¿Roma?) a derecha y leyenda [L C]ALPVRN AED. C [S] CN. BA[EBI GLAB] alrededor.

Rev.: Proa de nave a derecha, delante caduceo alado y encima victoria coronando a derecha, con leyenda SAGV bajo exergo.

DCPH 48, Ripollès \& Llorens 2002, 470/391-395

Coordenadas: 358575-4740312.

12. CALAGURRIS. Emisión anterior a 27 a. de C. (27-11 a. de C. según DCPH).
Ae. As. 29,42 mm. 12,10 g. Cuño 12 h.

Anv.: Cabeza desnuda de Octavio a derecha y leyenda II.VIR (a la izquierda) MVN.CAL (a la derecha).

Rev.: Toro a derecha con leyendas Q. ANTONI (encima) y L.FABI (bajo exergo).

DCPH 12, RPC 438.

Coordenadas: 358676-4740551.

13. CALAGURRIS. Emisión anterior a 27 a. de C. (27-11 a. de C. según DCPH).

Ae. As partido. ¿25? mm. 3,70 g. Cuño $7 \mathrm{~h}$.

Anv.: cabeza de Octavio (parte inferior) a derecha y leyenda I[I VIR] (a la izquierda) MVN [CAL] (a la derecha).

Rev.: Toro (parte superior) a derecha con leyendas Q.ANTONI (encima) y [L FABI (bajo exergo)].

DCPH 12, RPC 438.

Coordenadas: 358667-4740483.

14. CALAGURRIS. Emisión anterior a 27 a. de C. (27-11 a. de C. según $D C P H)$

Ae. As partido. ¿26? Mm. 4,70 g. Cuño 5 h.

Anv.: cabeza de Octavio (parte izquierda) a derecha y leyenda [I]I.VIR (a la izquierda) [MVN CAL (a la derecha)].

Rev.: Toro (parte trasera) a derecha con leyendas Q.ANT[ONI] (encima) y L [FABI (bajo exergo)].

DCPH 12, RPC 438.

Coordenadas: 358576-4740379.

15. CALAGURRIS. Emisión posterior a 27 a. de C. (ca 12-11 a. de C. según DCPH).

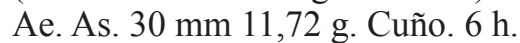

Anv.: Cabeza desnuda de Octavio a derecha y leyenda MVN.CAL (a la izquierda) IMP.AVGUS (a la derecha). Rev.: Toro a derecha con leyendas II.VIR / L.BAEBIO (encima) y P.ANTESTIO (bajo exergo).

DCPH 13, RPC 439.

Coordenadas: 358681-4740537.

16. CALAGURRIS. Emisión posterior a 27 a. de C. (ca 12-11 a. de C. según DCPH).

Ae. As partido. ¿29? mm. 5,27 g. Cuño 2 h.

Anv.: Cabeza desnuda de Octavio a derecha y leyenda [MVN.CAL (a la izquierda)] IMP.AVGUS (a la derecha). Rev.: Toro (parte inferior) a derecha y leyendas [II.VIR / L.BAEBIO (encima)] y P.ANTESTIO bajo exergo. DCPH 13, RPC 439.

Coordenadas: 358645-4740515.

17. BILBILIS. Emisión de entre los años 27 a. de C. y 23 a. de C.

Ae. As. 27,30 mm. 11,50 g. Cuño 11 h.

Anv.: Cabeza de Octavio a derecha y leyenda BILBILI detrás.

Rev.: Jinete lancero a derecha y leyenda ITALICA sobre exergo.

DCPH 9, RPC 388.

Coordenadas: 358735-4740630. 


\section{DESCONOCIDA.}

Ae. As perforado. 25,64 mm. 6,50 g.

Anv.: Frustra.

Rev.: Frustra.

Coordenadas: 358681-4740486.

19. ¿ROMA?.

Ae. As partido. $24,71 \mathrm{~mm} .10,20 \mathrm{~g}$.

Anv.: Varios trazos horizontales paralelos que podrán corresponderse con una proa de galera

Rev.: Frustra.

Coordenadas: 358754-4740615.

\section{DESCONOCIDA.}

Ae. As partido. $31 \mathrm{~mm}$. 10,90 g.

Anv.: Frustra.

Rev.: Frustra.

Coordenadas: 358807-4740556.

\section{DESCONOCIDA4 4 .}

Ae. As partido. ¿30? mm. 12,00 g.

Anv.: Frustra.

Rev.: Frustra.

Coordenadas: 358689-4740515.

Entre el campamento principal y el castro, en la zona por la que produjo el asalto romano y cerca de los restos de la circunvalación (Fig. 11):

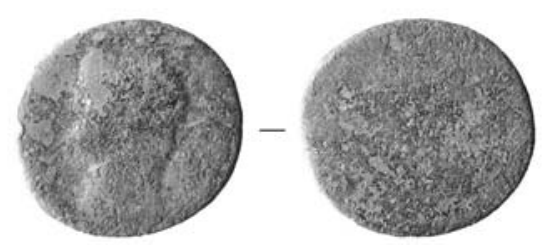

La Loma 22

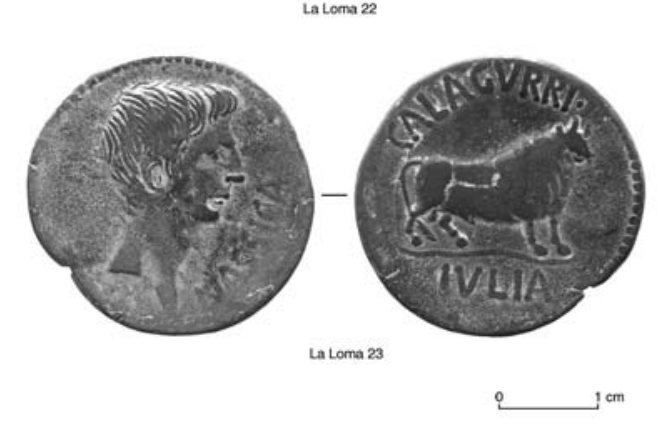

Figura 11: As de procedencia desconocida encontrado entre El Castro y el campamento romano de La Loma y as de Calagurris del castellum B.

4. Aunque tanto esta moneda como la anterior están tan desgastadas que resulta imposible apreciar nada en ellas, tanto su tamaño como los restos de un rebaje característico en el borde exterior nos hacen plantear la posibilidad de que se trate de antiguos ases republicanos de alguna de las series con cabeza bifronte de Jano en el anverso y una proa de galera en el reverso. Se trataría de monedas del mismo tipo que los $n^{\circ}$ 10 y 19 -éste con más dudas- de esta colección.

\section{DESCONOCIDA ${ }^{5}$.}

Ae. As. $22 \mathrm{~mm}$. 9,00 g.

Anv: Cabeza a izquierda.

Rev.: Frustra.

Coordenadas: 358445-4740466.

En el interior del castellum B (Fig. 11):

23. CALAGURRIS. Emisión de los años 40-30 a. de C. (posterior a 27 a. de C. según $D C P H$ ).

Ae. As. 27,63 mm. 10,80 g. Cuño 12 h.

Anv.: Cabeza desnuda de Octavio a derecha y leyenda NASSICA delante.

Rev.: Toro a derecha y leyenda CALAGURRI. (encima) IVLIA (bajo exergo).

DCPH 5, RPC 431.

Coordenadas: 357669-4739557.

El ejemplar $\mathrm{n}^{\mathrm{o}} 1$, procedente del oppidum de «El Castro», se localizó al exterior del recinto fortificado, aunque pegado a la muralla, en la esquina nororiental. Las piezas $n^{\circ} 2$ a 21, recogidas en el campamento principal, aparecieron dispersas por casi toda la superficie de éste, junto a otro gran número de materiales militares romanos: tachuelas de sandalia, objetos relacionados con la vestimenta de los legionarios, clavijas y regatones de tiendas de campaña, herramientas, armas, atalajes de caballería, etc. (Peralta, 2007). Como ya se ha comentado anteriormente, la moneda recogida entre el castro y el campamento principal, la $\mathrm{n}^{\circ} 22$, se encontraba en la zona por la que tuvo lugar el asalto romano; mientras que la última, la $\mathrm{n}^{\mathrm{o}} 23$, procede del castellum B.

La presencia de denarios de la ceca de Turiasu, como el del oppidum de El Castro $\left(\mathrm{n}^{\circ} 1\right)$, es relativamente frecuente en niveles de la II Edad del Hierro de algunos castros cántabros. En un trabajo reciente (Bolado, 2009) se recogen ejemplares de La Ulaña, Monte Cildá y Las Rabas, así como otro procedente de un hallazgo fortuito en el casco urbano de Soto-Iruz. En todos los casos comentados se trata de monedas muy similares a la de La Loma, pertenecientes a la misma serie y con una cronología de finales del siglo II a. de C. (Gozalbes, 2009, 133 y ss.). Su alta representación

5. Aunque resulta imposible identificar de qué moneda se trata, por causa de su pésimo estado de conservación, creemos que podríamos encontrarnos ante un as con efigie de Marco Antonio, de alguna ceca oriental; del tipo de los acuñados entre 39 y 36 a. de C. en Corinto (RPC 1124). Sin embargo, los mismos elementos que nos hacen plantear esa hipotética identificación - cabeza mirando a la izquierda, cuello ancho y corto- permitirían ver en esta pieza algún as altoimperial, alejado ya de las cronologías del yacimiento y del episodio bélico que dio origen al conjunto numismático presentado en este trabajo. Su presencia en una zona fuera de las estructuras -castro, campamento y castella- podría abogar, de confirmarse esa datación tardía, por su no relación con el asalto y destrucción del oppidum de El Castro durante las Guerras Cántabras. 
en la Cantabria anterior a la conquista podría explicarse por la intervención de mercenarios cántabros en las guerras sertorianas, aunque quizá sea más sencillo achacarlo a la vía de comunicación natural que supone el valle del Ebro y que une el sector central de la cordillera Cantábrica con la zona media del curso de este río (Bolado, 2009). El ejemplar de La Loma, dado el contexto de su hallazgo, también podría ponerse en relación con la propia conquista de Cantabria, ya que se ha señalado la existencia de un uso tardío de esas monedas en lugares alejados de la ceca de origen y asociado a la presencia del ejército romano (Gozalbes, $2009,87)$. Tanto en este caso como en la mayor parte de los recuperados en el territorio de los cántabros, los denarios de Turiasu carecen del desgaste propio de la moneda que ha circulado (Bolado, 2009, 334).

Entre los cinco denarios romanos procedentes del campamento principal, encontramos una moneda republicana acuñada en Roma a comienzos del siglo I a. de C. ( $\left.n^{\circ} 2\right)$; otra pieza del segundo triunvirato, emitida en Asia Menor a inicios de la segunda mitad de ese mismo siglo ( $\left.n^{\circ} 3\right)$; y tres monedas acuñadas por Marco Antonio ( $\mathrm{n}^{\circ}$ 4-6) para pagar a sus tropas durante la guerra con Octavio, inmediatamente antes de la batalla de Actium. La presencia de plata republicana en los campamentos de las guerras de conquista del norte de Hispania es bastante habitual. Los denarios que forman el conjunto de la Espina del Gallego (Peralta, 1999a, 229), los recuperados en La Muela (Martínez Velasco, 2009) o la pieza cesariana de La Carisa (Gil y García-Bellido, 2006) son algunos de los ejemplos más importantes entre los establecimientos temporales. En los asentamientos permanentes, como Astorga, León o Herrera de Pisuerga, entre otros, consta la presencia de denarios de esa cronología (García-Bellido, 2006, 633-634). Las piezas triunvirales, sobre todo las acuñadas por Marco Antonio con el nombre de sus legiones en el reverso, también son conocidas en esos establecimientos militares permanentes, con dos ejemplares en Herrera de Pisuerga y otro en Lugo (GarcíaBellido, 2006, 633-634).

En cuanto al desgaste de estas monedas de plata, puede observarse cómo, junto a piezas $-\mathrm{n}^{\mathrm{o}} 3,5 \mathrm{y}$ 6- que parecen haber circulado bastante, coexisten otras, como la $n^{\circ} 4$, en perfecto estado; lo que no deja de ser llamativo, ya que trata de denarios muy similares y acuñados en las mismas fechas. El caso de la $n^{\circ} 3$ puede explicarse por tratarse de un denario forrado. En cuanto a la $n^{\circ} 2$, la más antigua de todo el conjunto, hay que destacar que presenta un desgaste menor que algunas de las acuñadas entre 40 y 50 años más tarde.

Para la acuñación saguntina de L. Calpurnius y Cn. Baebius ( $\left.{ }^{\circ} 11\right)$, datada según $\mathrm{CNH}$ en el segundo tercio del siglo II a. de C., Ripollés y Llorens (2002) proponen una cronología preagustea y posterior a 56 a. de C., ya que la incluyen entre las emisiones correspondientes al periodo en el que la ciudad tuvo estatus de colonia.
En cuanto a la moneda de bronce del valle del Ebro y zonas aledañas, de nuevo nos encontramos con una constante detectada en otros yacimientos de las mismas características y cronología: la presencia abundante tanto de acuñaciones antiguas, de los siglos II-I a. de C., como de otras más cercanas al inicio de las campañas augusteas en el norte peninsular. Ases del mismo tipo de los reseñados en este trabajo aparecen en todos los escenarios relacionados con el conflicto, tanto en los campamentos de campaña como en los establecimientos permanentes -El Cincho, La Carisa, La Muela, Petavonium, Asturica, Legio, Herrera de Pisuerga, etc.- lo que confirma que el principal abastecimiento de moneda de bronce al ejército que participa en las Guerras Cántabras se hizo desde esa zona (García-Be1lido, 2006, 635, 638). En el asedio de La Loma, sin tener en cuenta el denario de Turiaso hallado en El Castro $\left(n^{\circ} 1\right)$, un $47,36 \%$ de las monedas recuperadas proceden de cecas del valle del Ebro (Fig. 12). Además, su proporción contrasta con la presencia prácticamente testimonial de acuñaciones de otras zonas de Hispania, con un solo ejemplar de Sagunto. Dentro de ese grupo, las acuñaciones de Calagurris suponen dos tercios del total, lo que refuerza la idea expuesta por GarcíaBellido (2004) sobre el carácter militar de esta ceca en época augustea. Otra cuestión, que discutiremos más adelante, es cuándo comienza a desempeñar este papel la ceca calagurritana, en relación con la cronología de las monedas $\mathrm{n}^{\circ} 12-16$, que consideramos contemporánea a las Guerras Cántabras, varios años anterior a la propuesta en otros trabajos (García-Bellido y Blázquez Cerrato, 2003; García-Bellido, 2004).

La llegada de esta importante cantidad de moneda del valle del Ebro a los escenarios de las Guerras Cántabras se puede explicar por dos razones: por un lado, porque el suministro de numerario a las tropas que participan en estas campañas se realiza desde las cecas de ese ámbito geográfico, lo que nos estaría mostrando los patrones de abastecimiento de moneda en el ámbito militar; y por otro, porque son las propias

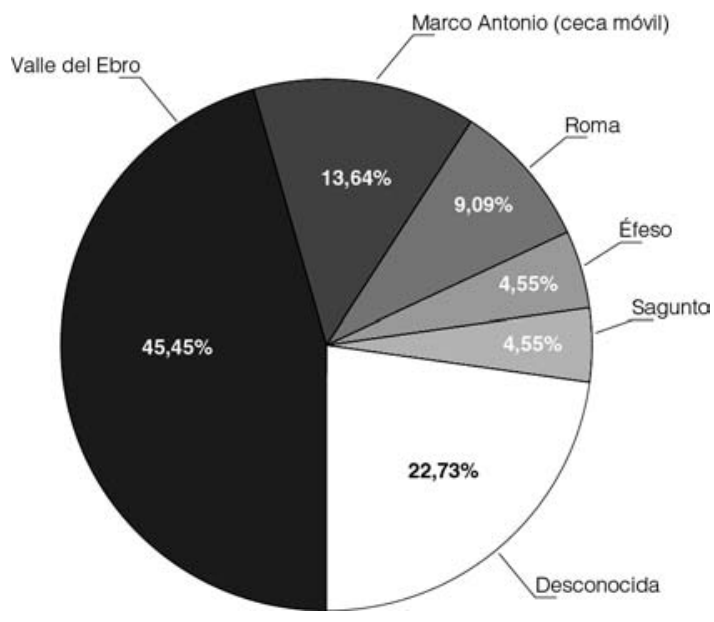

Figura 12: Procedencia de las monedas del campamento y del castellum B de La Loma. 
tropas quienes se abastecen de moneda en esa zona, de camino hacia el frente, lo que nos pone tras la pista de la ruta seguida por los contingentes legionarios.

Como es frecuente en los contextos militares del norte de la península Ibérica (Blázquez, 1995), en La Loma hay una cantidad significativa de moneda partida. En este caso, la partición únicamente afecta a las monedas de bronce. Hay siete unidades partidas, lo que supone un 46,66\% del total de monedas de ese metal (15) y casi un tercio si tenemos en cuenta el cómputo global. Todas están partidas a la mitad, excepto en el caso de la emisión de la serie Jano-Proa $\left(n^{\circ} 10\right)$, en la que la fracción conservada se corresponde con algo más de media moneda. En cuanto a la procedencia de las monedas partidas, sólo se puede establecer en la mitad de los casos, ya que tres de ellas son ilegibles. Aparte del ejemplar de la ceca de Roma mencionado $\left(n^{\circ} 10\right)$, los otros tres casos son monedas recién acuñadas de la ceca de Calagurris, dos emisiones de Q. Antonius y L Fabius ( $\mathrm{n}^{\mathrm{o}} 15$ y n $\left.^{\circ} 16\right)$ y una de L. Baebius y P. Antestius $\left(n^{\circ} 14\right)$.

Estos datos sobre moneda partida contribuyen a respaldar la interpretación que han realizado GarcíaBellido (2004, 44-45) y Blázquez (2006, 530 ss.) sobre este fenómeno, desvinculándolo de la reforma metrológica de Augusto y relacionándolo con la necesidad de moneda fraccionaria en los ámbitos militares. Si la colección de Andagoste, con un 50\% de moneda partida en un contexto militar fechado en torno a 44-30 a. de C., ha sido una pieza clave para defender esta tesis; y los estudios de los campamentos romanos estables del norte realizados por Blázquez (2006) han detectado la continuidad del fenómeno vinculado al ejército, el asedio de La Loma aporta una valiosa información para el periodo de las Guerras Cántabras, momento sobre el que la documentación era más escasa. En este sentido, las pautas de partición detectadas en este escenario dan si cabe más valor a los testimonios de otros campamentos de campaña relacionados con el mismo conflicto: un as de Calagurris (RPC 433-435), partido a la mitad, recuperado en El Cincho (Morillo y Gómez, 2006), y un as de Calagurris emitido por Q. Antonius y L Fabius, partido a la mitad, procedente de La Muela (Martínez Velasco, 2009). En todo caso, conviene tener presente la existencia de moneda partida en momentos cronológicos anteriores al de Andagoste y en otras zonas de la península, lo que descartaría que la práctica de la partición de ases hubiese llegado a Hispania desde Galia de la mano de las tropas cesarianas, como se ha propuesto en alguna ocasión (García-Bellido, 2004, 45). A ese respecto resulta altamente significativo el yacimiento catalán del Camp de les Lloses, interpretado como un vicus militar y con presencia de moneda ibérica partida tanto en contextos cerrados fechados entre finales del siglo II y principios del I a. de C. como en otros de finales del I a. de C. (Durán, 2009, 22-23, 27 y 38 y ss.). Los ejemplos procedentes del territorio de Sagunto (Ripollès y Llorens, 2002, 233) o del campamento romano de la II Guerra Púnica de La Palma, en el delta del Ebro -en ese caso, dos piezas helenísticas de plata partidas-(Noguera, 2008, 35), contribuyen a ampliar tanto el marco geográfico como el cronológico de un fenómeno que parece ser bastante anterior al período de las Guerras Civiles de finales de la República.

Las monedas de bronce, tanto los ases o unidades como las fracciones, también presentan distintos grados de desgaste. Desde las muy desgastadas, como las $\mathrm{n}^{\mathrm{o}} 18,19,20,21$ y $22 \mathrm{y}$, en menor medida, las $\mathrm{n}^{\mathrm{o}} 10 \mathrm{y}$ 14; hasta las que apenas presentan erosión, como las $n^{\circ}$ 12,13 y 23; pasando por aquéllas que presentan un desgaste intermedio, caso de las $\mathrm{n}^{\mathrm{o}} 7,8,9 \mathrm{y}$, algo menos, las $n^{\circ} 15,16$ y 17 . Desde un punto de vista cronológico, estas diferencias en el desgaste de las piezas serían perfectamente coherentes con su mayor o menor antigüedad. Así, los ases partidos que hemos identificado, segura o hipotéticamente, como viejas monedas republicanas están tan gastados que sólo uno de ellos es reconocible sin lugar a dudas. Esto se debería, sin duda, a sus largos años de circulación. Por su parte, las mayor parte de las unidades indígenas, también de cronología antigua, presentan un marcado desgaste, aunque mucho menor que las anteriores. De hecho, todas son perfectamente identificables y sus leyendas legibles, lo que podría atribuirse a una menor circulación. Finalmente, entre la moneda hispanorromana encontramos piezas que comparten erosión con el grupo anterior y otras, que, al contrario, apenas están desgastadas. Entre las primeras, los ases de Sagunto y Bilbilis son los más gastados, junto con una de las monedas partidas de Calagurris sobre la que volveremos en breve. Dos de las piezas de esta ceca presentan un desgaste apreciable y otra uno intermedio, mientras que las otras dos restantes, un as entero y otro partido, apenas dan muestra de él. Un breve análisis del conjunto calagurritano ofrece algunos resultados llamativos, ya que el desgaste no se corresponde con la antigüedad de las acuñaciones. La pieza más antigua, la $n^{\circ} 23$, está menos desgastada que las dos más recientes, la 15 y la 16; mientras que las 12 y 13 , en una posición cronológica intermedia, son las menos erosionadas. Sin embargo, la $n^{\circ} 14$, de la misma serie que estas dos últimas, es, con mucha diferencia, la pieza más deteriorada de todas las de Calagurris. De todo esto se desprende que no todas las monedas tuvieron la misma vida y que, independientemente de su fecha de acuñación, mientras unas circularon mucho y se desgastaron en consecuencia, otras, pese a ser más antiguas, no se movieron demasiado y llegaron a su fin en mucho mejor estado.

\section{CAMPAMENTO ROMANO DE CASTILLEJO}

\subsection{EL YACIMIENTO}

Coordenadas UTM: X: 405968. Y: 4737301.

Lugar: Castillejo o La Lastra.

Localidad: Pomar de Valdivia.

Municipio: Pomar de Valdivia (Palencia). 
En la conquista del territorio de los cántabros el avance principal de las legiones tuvo que producirse por el valle del Alto Pisuerga y, durante dicho avance, hubo de ser expugnado necesariamente, entre otros, el oppidum de Monte Bernorio (Villarén), clave para el control de esta comarca y para cualquier ulterior avance hacia el norte en dirección al nacimiento del Ebro y los pasos de la Cordillera Cantábrica. Las recientes excavaciones en este yacimiento han encontrado evidencias de que fue atacado por el ejército romano: puntas de flecha romanas en la muralla sur y niveles de incendio y destrucción detrás de la misma (Torres, 2007; Peralta, 2009a, 259 ss.).

Cerca de él, a unos 2'5 km, dimos a conocer hace algunos años (Peralta, 2001b, 175 ss.; 2002b, 227ss.; 2003, 301 ss.; 2004b, 33ss.; 2009a, 259 ss.) la existencia de un importante campamento romano de campaña en el alto de Castillejo o de La Lastra (Pomar de Valdivia). Ha suministrado equipamiento militar romano similar al de La Loma, aunque menos abundante, y materiales numismáticos que señalan su cronología augustea. Dispone de un recinto central de planta rectangular de 18'38 ha (Fig. 13) dotado de una puerta en clavicula. Su vallum está formado por un amurallamiento de piedra de 2'25 $\mathrm{m}$ de anchura y por una fossa fastigata, de fondo plano y perfil trapezoidal, de 1'80 $\mathrm{m}$ de anchura (VI pies) y $90 \mathrm{~cm}$ de profundidad (III pies). Fuera dispone de otra línea defensiva que encierra una superficie que supera las 41 ha. El corte en este

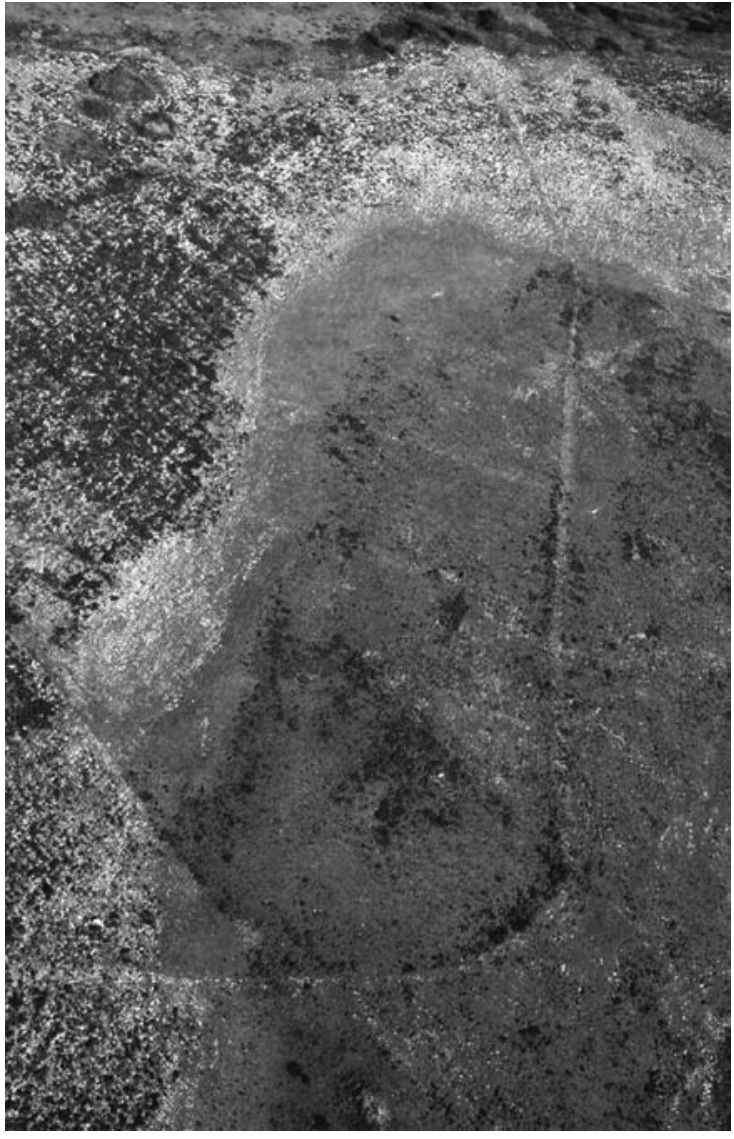

Figura 13: Vista aérea del campamento de Castillejo.

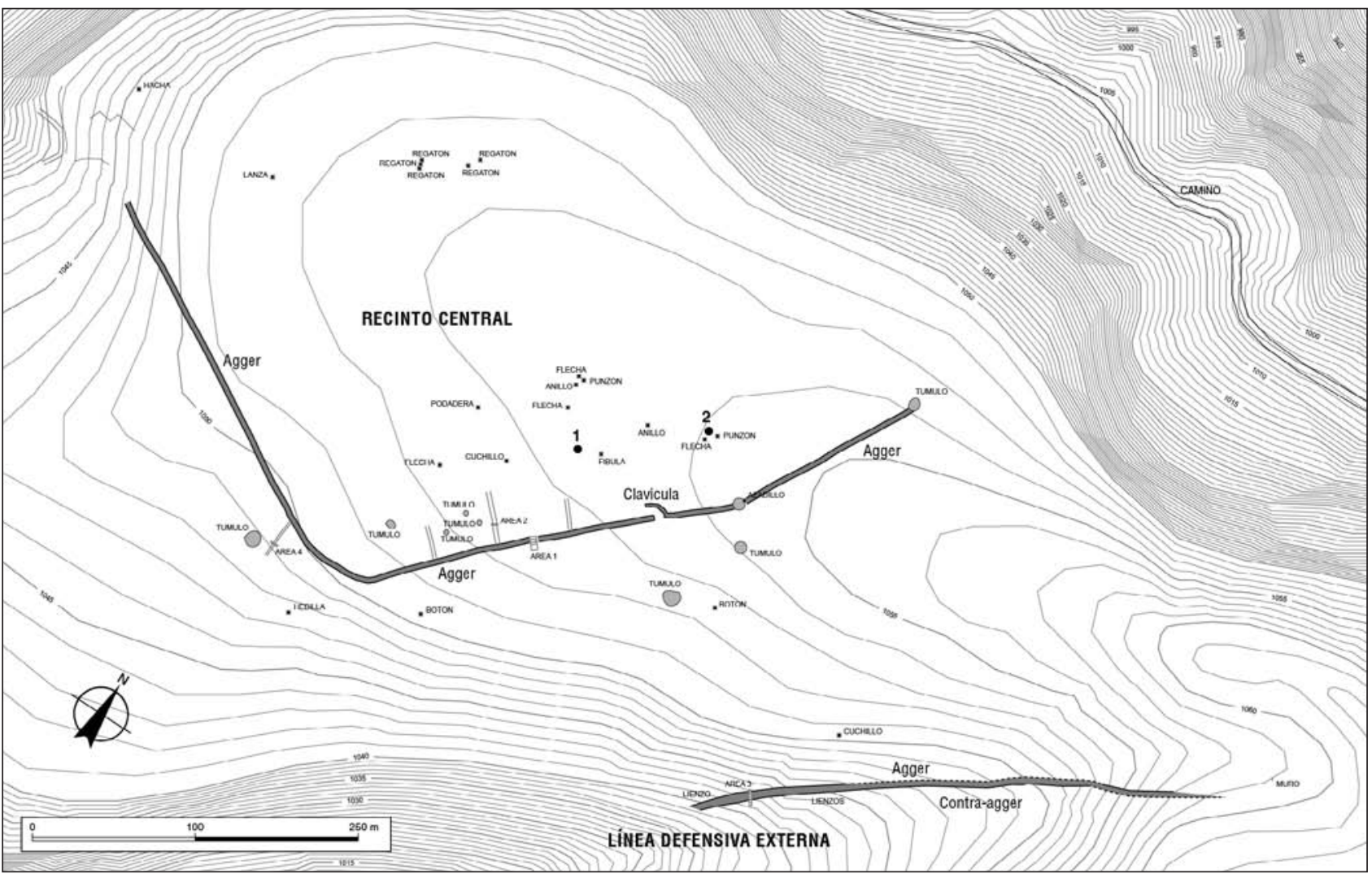

Figura 14: Plano de distribución de los hallazgos en el campamento de Castillejo, con indicación del lugar donde aparecieron las monedas. 
vallum exterior permitió documentar que el terraplén de tierra y muro del agger tuvo originalmente 1' $80 \mathrm{~m}$ de altura (VI pies). Delante tiene una fossa fastigata, de fondo plano y perfil trapezoidal, de $5 \mathrm{~m}$ de anchura (XVII pies) y 1'5 $\mathrm{m}$ de profundidad. Las grandes dimensiones del campamento, teniendo en cuenta que en un campamento de campaña las tropas acampaban más concentradas, indica que tuvo que tratarse de un castra aestiva para más de una legión.

Durante las campañas arqueológicas del 20002002 el yacimiento proporcionó diverso armamento y utillaje militar, así como dos monedas (Fig. 14).

\subsection{LAS MONEDAS}

En el interior del campamento de Castillejo únicamente se recuperaron, en el transcurso de la excavación llevada a cabo en el 2001, dos monedas (Fig. 15):

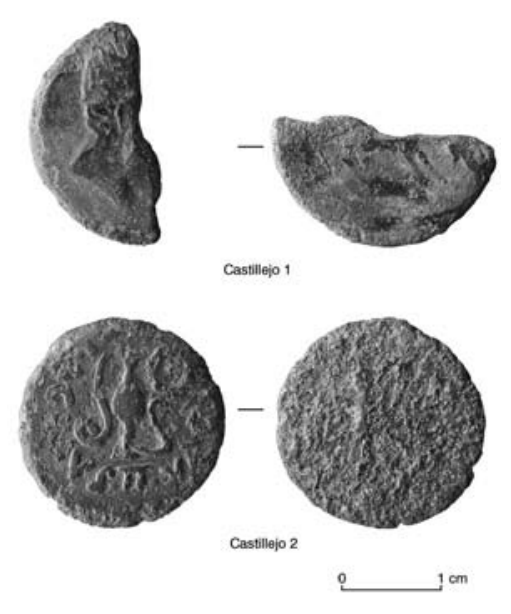

Figura 15: Ases encontrados en el campamento de Castillejo.

1. ILTIRTA. Emisión de época de las Guerras Sertorianas (82-72 a. de C.)

Ae. As partido. ¿22? Mm. 3,17 g. Cuño $11 \mathrm{~h}$

Anv.: cabeza masculina (parte posterior) a derecha

Rev.: lobo (parte inferior del cuerpo, patas delanteras y fauces) a derecha

DCPH 43, CNH 181/40-41

2. CARTAGO NOVA. Emisión en torno al año 44 a. de $\mathrm{C}$.

Ae. Semis. 20 mm. 3,73 g. Cuño $7 \mathrm{~h}$

Anv.: Águila de Júpiter (sobre haz de rayos) a derecha y leyenda [L IVNIVS II VIR QVIN AVG] alrededor

Rev.: Litio o praefículo, jarra o vaso sagrado y patera y leyenda L.ACILIVS.II.VIR [QVIN AVG]

DCPH 7, RPC 152

El reducido tamaño de la muestra procedente de este yacimiento, con sólo dos unidades, impide que puedan hacerse grandes consideraciones acerca de su cronología y carácter.
La $\mathrm{n}^{\circ} 1$ es una pieza de Iltirta, la Ilerda romana y actual Lleida, acuñada en época sertoriana, entre los años 80 y 72 a. de C. El hecho de que esté partida, característico de ámbitos militares (Blázquez, 1995; García-Bellido, 2004; Blázquez, 2006), viene a añadir un caso más en contextos de las Guerras Cántabras a los comentados más arriba.

En cuanto a la no 2, Beltrán (1949) dató la emisión en 37 a. de C., considerando que la leyenda AVGVR hacía referencia a la fecha en la que Octavio recibe ese título. Sin embargo, la leyenda se refiere en realidad a los magistrados de la ciudad. A partir de esta interpretación, Llorens (1994) propone una cronología posterior a 67-55 a. de C., momento en el que se acuñan denarios romanos que sirven de modelo iconográfico a esta moneda. En un trabajo reciente de Abascal (2002) sobre la promoción colonial de Cartago Nova, se establece el momento del desempeño de las magistraturas referidas en ella por parte de L. Iunius y L. Acilius en torno al año 44 a. de C. Desconocemos la existencia de otros semises de esta acuñación en yacimientos relacionados con las campañas augusteas en el norte de la península Ibérica, y en general la presencia de moneda fraccionaria de bronce en los contextos militares de la zona es muy poco frecuente. Sirva como ejemplo el caso de Herrera de Pisuerga, donde de 182 monedas de época de Augusto o anteriores 168 son de bronce y únicamente hay tres semises (Morillo y Gómez Barreiro 2006). La ceca de Cartago Nova también es excepcional en estos ámbitos, ya que sólo aparece otro ejemplar en Herrera de Pisuerga: un as acuñado durante el principado de Augusto y fechado en torno al año 13 a. de C. (Morillo y Gómez Barreiro 2006, 430).

Ambas piezas, muy desgastadas, presentan cronologías perfectamente compatibles con el papel que ha venido proponiéndose para el campamento de Castillejo dentro del desarrollo de las campañas romanas en el interior del territorio de los Cántabros: su relación con el asalto y toma de la cercana fortaleza de Monte Bernorio (Peralta, 2003; 2004; 2007 y 2009) en un momento temprano de la guerra, alrededor de los años 26-25 a. de C., durante la campaña de Octavio o, más probablemente, la del legado de la Tarraconense Cayo Antistio Veto. Los trabajos arqueológicos llevados a cabo en Castillejo documentaron la destrucción intencionada -arrasamiento de los aggeres y relleno de los fosos- de las defensas del campamento, coincidiendo con su abandono por parte de las tropas que lo levantaron. La reciente constatación arqueológica de la presencia de una guarnición romana asentada sobre las ruinas del oppidum indígena del Bernorio (Torres y Serna, 2010, 79-85), guarnición que perduró más allá del cambio de era y que incluso dio lugar a la aparición de un pequeño núcleo civil asociado ${ }^{6}$, nos hace supo-

6. Las novedades de las excavaciones en este yacimiento, entre las que se incluye la existencia de un hábitat civil surgido alrededor de la guarnición romana y que perdura más allá del 
ner que el establecimiento de Castillejo no fue reutilizado en el transcurso de las campañas posteriores ni albergó en su interior un puesto defensivo menor, de tipo castellum o turris, como los presentes en algunos otros campamentos de las Guerras Cántabras (Morillo et alii, 2008, 115; Bolado et alii, en prensa).

\section{CAMPAMENTO ROMANO DE EL ALAMBRE}

\subsection{EL YACIMIENTO}

Coordenadas UTM: X: 404916. Y: 4732010.

Lugar: El Alambre.

Localidad: Fuencaliente de Lucio.

Municipio: Valle de Valdelucio (Burgos).

Este importante yacimiento campamental romano fue descubierto durante nuestra campaña de prospecciones arqueológicas del año 2003. Debemos la primera referencia a la existencia de un posible castro en este lugar al investigador Miguel Angel Fraile López. Tras visitar el lugar junto a Federico Fernández y Roberto Ayllón comprobamos que se trataba de un castra aestiva romano. Con posterioridad, Miguel Ángel Fraile se ha ocupado del enclave prefiriendo interpretarlo como un asentamiento castreño de la Edad del Hierro (Fraile, 2006, 19 y 86).

Se encuentra en un alto situado al sudoeste de Fuencaliente de Lucio, a menos de $1 \mathrm{~km}$ de esta localidad. El paraje se denomina El Alambre y dispone de una superficie llana de cerca de 8 ha, bordeada de pendientes bastante pronunciadas. A los pies de esta loma, por el sur discurre el arroyo de El Alambre y por el este y el norte el río Lucio; hacia el oeste el terreno asciende hasta el alto rocoso y parcialmente cubierto de encina de La Lastrona.

El campamento está fortificado con un agger de piedra y tierra que forma un terraplén visible en todo su perímetro. En algunos puntos este terraplén alcanza todavía una altura de unos dos metros y medio. El borde del terraplén, especialmente en el perímetro sur, dispone de restos claros de un amurallamiento consistente en una hilera de bloques de piedra hincados. A los pies del agger se intuye la presencia de un foso, apreciable con más claridad en las fotos aéreas (Fig. 16).

El tamaño del recinto, cercano a las 8 ha, nos indica que probablemente se trate de un campamento temporal de campaña de una legión. La planta visible en la foto aérea se desvía ligeramente de la característica planta rectangular con ángulos redondeados, adaptándose a la topografía de la vaguada existente en el centro del perímetro oeste, donde el terraplén evita

cambio de era, han sido recogidas en el artículo de M. Redondo «La huella romana de Monte Bernorio» en el Diario Palentino Digital del 5 de octubre de 2008.

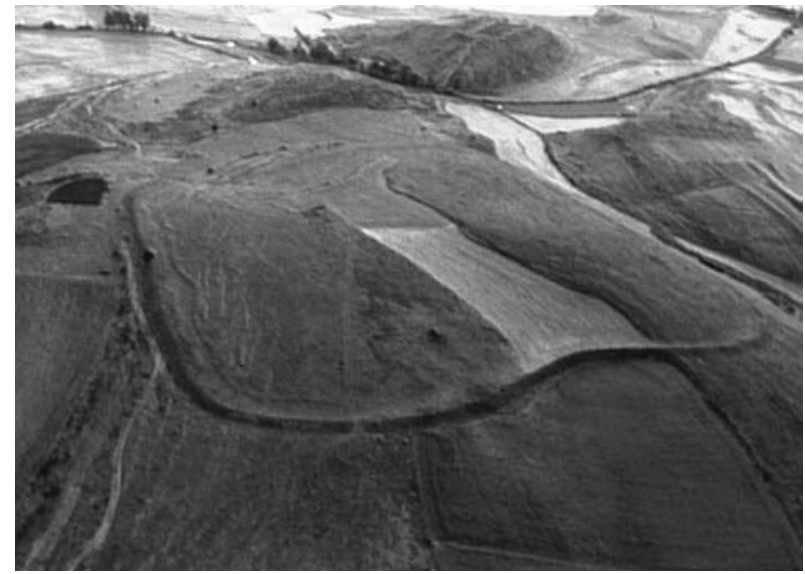

Figura 16: Vista aérea del campamento de El Alambre.

la depresión del terreno retrocediendo ligeramente en curva hacia el interior del campamento.

En superficie se han encontrado algunos pequeños fragmentos de lo que parece cerámica común romana $\mathrm{y}$ un molino barquiforme de arenisca, probablemente protohistórico. Más significativos para determinar el carácter campamental romano del emplazamiento son otros materiales de superficie procedentes del talud exterior del agger y encontrados en el perímetro

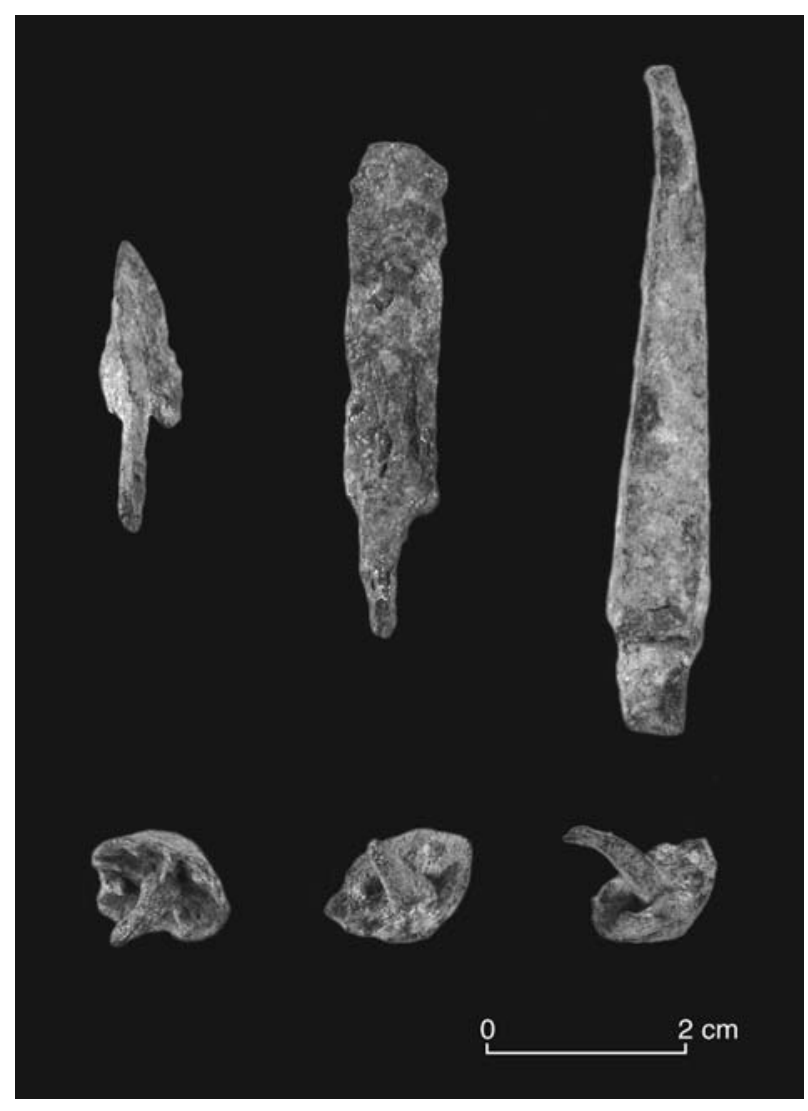

Figura 17: Objetos metálicos encontrados en el campamento de El Alambre: punta de flecha, puntas de pilum y tachuelas de caliga. 
sudoeste y sur: una punta de pilum de sección piramidal alargada, dos tachuelas cónicas de caliga con la característica decoración de glóbulos y cruceta; y una punta de flecha romana de hierro de tres aletas encontrada en el interior del campamento, detrás del ángulo sudoeste (Fig. 17).

La única moneda documentada apareció, durante la prospección, en la franja roturada de la zona central del campamento.

\subsection{LA MONEDA}

En el campamento de El Alambre se recuperó la siguiente moneda (Martínez Velasco, 2009, 522) (Fig. 18):

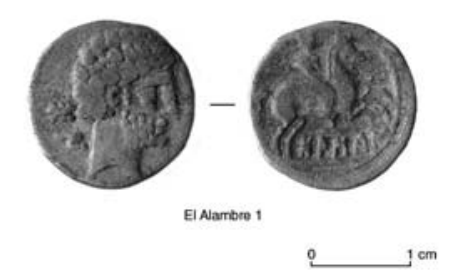

Figura 18: Denario de Bolskan encontrado en el campamento de El Alambre.

1. BOLSKAN. 82-72 a. de $\mathrm{C}^{7}$.

Ag. Denario. 17,5 mm. 2,3 g. Cuño $12 \mathrm{~h}$

Anv.: cabeza masculina barbada a derecha con leyenda bo.n detrás (a la izquierda)

Rev.: jinete lancero a derecha y leyenda bo.l.s.ka.n. sobre exergo

DCPH 9, CNH 212/13

Como hemos visto con anterioridad al tratar el ejemplar de Turiaso del oppidum de El Castro, los hallazgos de denarios pertenecientes a acuñaciones prerromanas del valle del Ebro -y zonas cercanas- son relativamente frecuentes en horizontes de la Segunda Edad del Hierro de la antigua Cantabria (Bolado, 2009). La presencia de esta moneda en el interior de un campamento romano de campaña ha sido relacionada, creemos que correctamente, con las campañas contra los Cántabros de 29-19 a. de C. (Martínez Velasco, 2009, 522). Piezas muy parecidas a ésta de El Alambre han sido recuperadas en yacimientos romanos de tipo militar, tanto anteriores como posteriores a esas fechas. En el campo de batalla de Andagoste (Cuartángo, Álava), que se fecha alrededor del año 44-30 a. de C., se

7. Aunque ésa -la de las Guerras Sertorianas- sea la fecha tradicional para las grandes acuñaciones de plata de Bolskan, es posible que haya que adelantar su cronología hasta las últimas décadas del siglo II a. de C., tal y como ha ocurrido con las de las cecas de Turiasu y Arekorata, cuyos denarios aparecen con frecuencia acompañando aquéllas en los tesoros datados en ese conflicto (Ripollés y Abascal, 2007, 35) recogió un ejemplar (Unzueta y Ocharán, 2006). Por otra parte, estos denarios de Bolskan también aparecen en algunos de los campamentos del limes renano (García-Bellido, 2004, 309), posteriores a la conclusión de las Guerras Cántabras. En territorio cántabro conocemos un denario similar al de El Alambre y que procede del yacimiento arqueológico de Retortillo (Vega de la Torre, 1982, 238), de carácter civil e identificado con la ciudad romana de Iuliobriga. Su presencia en este lugar, fundado muy probablemente ex novo -o sobre un establecimiento menor, de tipo aldea (Bolado et alii, en prensa) - en un momento no muy alejado en el tiempo del final de las hostilidades, tal como sugieren los materiales arqueológicos de sus niveles más antiguos (Cepeda et alii, 2009, 631-634), es una buena muestra de su circulación hasta fechas relativamente tardías.

\section{LA CRONOLOGÍA DE LOS ASES DUUNVIRA- LES DE CALAGURRIS}

La cronología de las series de monedas hispanolatinas de Calagurris ha sido objeto de la atención de los investigadores desde hace décadas, debido a las dudas que suscita y a pesar del gran número de ejemplares conocidos y su amplia distribución. Los ejemplares recuperados en el asedio de La Loma, un contexto relacionado con las Guerras Cántabras que cuenta con un marco cronológico muy concreto, entre 26 y 19 a. de C., aportan nuevos elementos a esta discusión cronológica.

El establecimiento de una cronología para estas acuñaciones ha estado unido, desde un primer momento y como veremos a continuación, a la fecha de constitución de la ciudad como municipium romano, ya que el inicio de las acuñaciones ha sido establecido por los diferentes autores en función del momento en el que han considerado que Calagurris recibió esa condición jurídica.

M. Grant (1946) había propuesto una fundación del municipium por parte de T. Statilio Tauro alrededor del 29-28 a. de C., fecha que señalaría la primera emisión. Este autor adelanta, además, las monedas en las que aparece la titulatura IMP AVGUSTUS a un momento posterior a 18 a. de C., ya que, según su interpretación, ésta tiene su origen en una emisión de denarios acuñados en Roma en esa fecha. Estos argumentos fueron puestos en duda por Ruiz Trapero en el que es, hasta la fecha, el único trabajo monográfico sobre las acuñaciones calagurritanas (Ruiz Trapero, 1968).

Esta autora señala que la municipalización debió producirse de manos de Julio César y establece una fecha de inicio de las emisiones monetales de hacia el año 36 a. de C. (Ruiz Trapero, 1968). La clasificación cronológica de las monedas se realiza atendiendo principalmente a criterios tipológicos. Según esta propuesta, los ejemplares recuperados en los campamentos de La Loma se ordenarían de la siguiente manera: 
la $\mathrm{n}^{\mathrm{o}} 23$, la más antigua y emitida en el momento de la fundación del municipium, alrededor del año 36 a. de C.; las $n^{0} 12,13$ y 14, pertenecientes a la que sería la primera emisión en la que aparecen los nombres de los magistrados, entre esa fecha y el año 27 a. de C.; y las $\mathrm{n}^{\mathrm{o}} 15$ y 16, con la mención del título Augustus, entre el 27 a. de C. y el 2 a. de C.

A. Beltrán (1984), por su parte, maneja una clasificación muy similar a la anterior, aunque con alguna ligera variante, como el adelanto de la fecha de la primera emisión a un momento cercano al año 42 a. de C. Por su parte U. Espinosa (1984) propone una nueva data para la constitución del municipio calagurritano: los años 31-30 a. de C. La nueva fecha se establece a partir del momento en el que tiene lugar el licenciamiento de la escolta personal de Octavio, formada por nativos de la ciudad, tras la batalla de Actium y el argumento principal manejado por este autor es la pretendida imposibilidad de que esa escolta estuviese formada por ciudadanos romanos. Aunque no ofrece cronologías para las diferentes emisiones, su propuesta haría que los años de emisión de los ejemplares de La Loma debieran rejuvenecerse sensiblemente respecto a lo planteado por Ruiz Trapero.

Según el más reciente repertorio de monedas prerromanas y romanas de la península Ibérica, el Diccionario de Cecas y Pueblos Hispánicos (DCPH) (García-Bellido y Blázquez Cerrato, 2003, 221 y ss.), la moneda $n^{\circ} 23$ se correspondería con la $5^{\mathrm{a}}$ emisión, acuñada después de 27 a. de C.; las monedas $n^{\circ} 12$, 13 y 14 pertenecerían a la $12^{\mathrm{a}}$ emisión, realizada entre 27 y 11 a. de C.; y las monedas $n^{0} 15$ y 16 serían de la $13^{a}$ emisión, alrededor de los años 12-11 a. de C. En una publicación posterior, García-Bellido (2004, 147) propone adelantar la fecha de las monedas con cabeza desnuda de Octavio y sin la presencia del título AVGVSTVS a cerca del año 15 a. de C., a partir del registro arqueológico del campamento de Oberaden, en el valle del Lippe, en Germania. Parece que para esta autora no existiría relación entre las primeras emisiones calagurritanas y la promoción a municipium, ya que sitúa este evento en el año 13 a. de C. ${ }^{8}$, en relación con la gran reforma administrativa de Augusto (García-Bellido, 2004, 307). Según esta nueva propuesta, las monedas $\mathrm{n}^{\mathrm{o}} 23,12,13$ y 14 de La Loma habrían de llevarse a alrededor de esas fechas de 15-13 a. de C., un momento muy posterior al fin de las campañas militares en Cantabria, mientras que los $\mathrm{n}^{\mathrm{o}} 15$ y 16 permanecerían en una fecha $c a$. 12-11 a. de C., aún más reciente y separada de los acontecimientos bélicos.

8. Sobre las fechas de la promoción municipal y las acuñaciones calagurritanas hay una cierta contradicción en este trabajo. Mientras que en la p. 50 se admite que hay acuñaciones de Calagurris en las que aparecen los II VIR en torno a 27-23 a. de C., más adelante en la p. 307 se hace coincidir la aparición de II VIR en las monedas con la fecha que esta autora supone para la promoción municipal, el 13 a. de C.
La principal razón para fechar esas emisiones de Calagurris alrededor de los años 12-11 a. de C. parece ser su presencia en los establecimientos militares romanos de época augustea del limes renano y de la «vía del Lippe», hacia el corazón de la efímera provincia de Germania Magna. Sin embargo, consideramos que esa presencia tiene un valor muy relativo en lo que atañe a la cronología de las propias monedas. En el caso del campamento de Oberaden, en uso entre los años 11 y 8 a. de C., únicamente se puede establecer un término ante quem para su acuñación, que sería necesariamente anterior a esos años, y no post quem. Sin embargo, la existencia de alguna de esas monedas en ese campamento parece que se ha convertido en una de las piedras angulares sobre las que descansa una buena parte de la seriación cronológica que encontramos en $D C P H$ y trabajos posteriores que lo toman como referencia. De hecho, se llega a fechar el conjunto de monedas hispánicas procedentes de ese yacimiento entre 13-11 a. de C. sin más razonamiento que su supuesta «homogeneidad» (García-Bellido, 2004, 146). En los campamentos del Lippe también aparecen monedas hispanas acuñadas con anterioridad a las guerras de conquista del norte peninsular y cuya cronología no se adelanta por el hecho de estar presentes en esos yacimientos, como ocurre con los denarios y ases pompeyanos, el as de Bilbilis o el quinario emeritense emitido por P. Carisio de Haltern (García-Be1lido, 2004, 135-137); el as de Segobriga de Oberaden (García-Bellido, 2004, 146); o las monedas de Emerita, Segobriga, Bilbilis y Celsa de Novaesium (GarcíaBellido, 2004, 153-154). Esos hallazgos demuestran que esas monedas siguen circulando entre las tropas romanas de la frontera del Rin mucho tiempo después de su acuñación en Hispania, por lo que considerar más antigua la fecha de las emisiones de Calagurris hasta hacerlas coetáneas con algunas de ellas no supondría ningún problema desde el punto de vista de la coherencia del registro arqueológico. De hecho, esos ases calagurritanos seguirían siendo más recientes que algunas de las piezas señaladas, acuñadas en la primera mitad del siglo I a. de C.

El segundo de los argumentos para ubicar cronológicamente las emisiones calagurritanas a las que pertenecen los ejemplares $n^{\circ} 15$ y 16 de La Loma parece tener que ver con la acuñación de moneda con la leyenda AVGUSTVS DIVI F por parte de varias cecas del valle del Ebro alrededor del año 13 a. de C. (Morillo y Gómez Barreiro, 2006, 470). Aunque Calagurris no emitió moneda con esa leyenda, de la lectura de determinados párrafos se desprende que se ha extrapolado esa situación a esa ciudad, aunque sin especificar los porqués (García-Bellido y Blázquez, 2001, 133; García-Bellido 2004, 147, 312-313). La única razón que se nos ocurre puede tener que ver con la presencia de la titulatura Imperator Augustus (IMP AVGVS) en las leyendas de los ases calagurritanos. Ya Grant (1946) había señalado la aparición del segundo de esos títulos en la monedas únicamente a 
partir de ciertas emisiones de Roma fechadas en 17 a. de C. Realmente desconocemos si se sigue ese mismo razonamiento, ya que no lo hemos visto citado expresamente en los trabajos que tratan el tema. Sin embargo, de ser así, creemos que se trata de un argumento equivocado, ya que existen acuñaciones anteriores a esa fecha en las que los títulos del Princeps son los mismos que los que aparecen en esas series calagurritanas de las que estamos tratando. Las monedas «de la caetra» o «del NO» (García-Bellido y Blázquez, 2001, 287), cuyos primeros tipos se fechan sin discusión en los años 27-26 a. de C. y en estrecha relación con las campañas militares en el norte peninsular, presentan a Octavio con la siguiente titulatura: IMPERATOR AVGVSTVS DIVI FILIVS. El segundo de esos títulos, en solitario o precedido de CAESAR, también aparece en las monedas acuñadas en Emerita Augusta por Publio Carisio alrededor de 23-20 a. de C. (Cebrián, 2008; Martini, 2008), tras la conquista de Cantabria y Asturia y antes de las últimas rebeliones de una parte de sus habitantes. En relación con la presencia del título AVGVSTVS en las monedas, 1o único que puede asegurarse es que las que lo llevan han de ser, por fuerza, posteriores al año 27 a. de C., que es cuando le es concedido a Octavio. En el caso de Calagurris, J. M. Blázquez Martínez (1973-74, 9) sostiene, siguiendo a Gil Farrés, que esas acuñaciones han de fecharse entre los años 27-25 a. de C.

Llegados a este punto, creemos que los materiales numismáticos recuperados en el asedio de La Loma que hemos presentado en este trabajo, al proceder de un contexto con unas características muy determinadas y que consideramos que puede fecharse con relativa seguridad, constituyen una aportación muy valiosa en este debate cronológico.

En primer lugar, es necesario prestar atención a esas características de los yacimientos que forman el asedio de La Loma, así como a los materiales arqueológicos que han proporcionado. Especialmente al campamento principal, ya que en él es donde se han recuperado la mayor parte de las monedas de Calagurris. Éste, como ya se ha adelantado, forma parte de un dispositivo de asedio a una fortaleza indígena, compuesto por varios establecimientos campamentales y estructuras en los que se repartirían los efectivos de una legión y algunas unidades auxiliares. De hecho, se trata del más importante del conjunto, ya que con sus casi 6 ha albergaría a la mayor parte del ejército romano protagonista de la acción. A la luz de los hallazgos arqueológicos resulta innegable que La Loma es el escenario de un hecho de armas: hay evidencias de un cerco romano al castro cántabro, con sus líneas de circunvalación y contravalación y sus castella; se han recogido cientos de puntas de flecha y de pila catapultaria, algunas de ellas incendiarias, arrojadas al interior del castro y en alguno de los campamentos; y se han documentado niveles de destrucción violenta del oppidum, asociados a restos humanos y a materiales militares romanos.
En lo relativo a los hallazgos numismáticos, dejando al margen los ejemplares de Calagurris, en todo el conjunto no se han localizado ejemplares cuya fecha de emisión pudiera ser posterior al año 23 a. de C. y que sí están presentes en otros establecimientos de campaña, como los campamentos de La Carisa (Gil y García-Bellido, 2006) y del Campo de las Cercas (Morillo y Fernández Ochoa, 2005, 168), o el castellum de La Muela (Martínez Velasco, 2009). De aceptar algunas de las cronologías propuestas (vid supra) para los ases calagurritanos que nos ocupan, una explicación a su presencia en este yacimiento pasaría por considerar la posibilidad de una ocupación del campamento principal prolongada en el tiempo más allá del fin de las hostilidades. O la existencia en su interior de una pequeña guarnición permanente de tipo castellum, como las detectadas arqueológicamente en Cildá (Peralta, 2008, 155) y en La Carisa9; o la que evidencian los materiales numismáticos ya mencionados del Campo de las Cercas. Sin embargo, existen una serie de argumentos que nos permiten descartar, en el estado actual de nuestros conocimientos sobre el conjunto, esas dos posibilidades.

No se ha observado la existencia de restos de edificaciones de carácter permanente, de tipo barracón, ni en el interior del recinto legionario principal ni en el de ninguno de los dos castella conocidos. En los campamentos en los que han sido localizados, los restos de esas estructuras, principalmente zócalos de piedra, eran visibles en superficie, como sucedía por ejemplo en Cildá o La Carisa (Camino et alii, 2001, 272, nota $3)$. En todos los casos se trataba de yacimientos caracterizados por una escasa potencia edáfica, como sucede en el campamento principal de La Loma. A esta ausencia de instalaciones permanentes habría que sumar la propia localización del campamento, en un lugar sin demasiado interés militar una vez concluida la función para la que fue levantado: la toma del castro. Los establecimientos militares temporales en los que se han documentado puestos permanentes posteriores a las Guerras Cántabras se sitúan en zonas de gran importancia estratégica, cuyo control era necesario mantener una vez terminadas las operaciones bélicas. En el caso concreto de Cildá y Campo de las Cercas, el objetivo era el control de la vía de altura de acceso a la costa utilizada durante la conquista (Bolado et alii, en prensa). Lo mismo sucede en La Carisa para el territorio central de la Asturia trasmontana (Camino et alii, 2005). Además y como se constata en otros escenarios similares, todo apunta a que una guarnición romana se instaló sobre las ruinas del oppidum asaltado de El Castro: la erección de una muralla interna que destruye niveles de habitación prerromanos

\footnotetext{
9. Información recogida en el artículo «El cuartel imperial de La Carisa», publicado en La Nueva España el día 14 de Octubre de 2007. Esos barracones también son citados en la página web oficial del yacimiento http://www.lacarisa.es.
} 
y la construcción de un agger de tierra sobre las ruinas de la muralla indígena en la zona nororiental del castro, detectada en las últimas campañas de excavación, parecen indicios sólidos al respecto. Como principal paralelo para ese tipo de comportamiento por parte de las tropas romanas encontramos lo sucedido en Monte Bernorio, donde se ha registrado una secuencia muy similar, con la destrucción violenta del castro seguida de una ocupación militar romana; en un principio más amplia y luego restringida a un castellum de dimensiones más reducidas (Torres Martínez y Serna, 2010, 79 ss.). Hay más casos de establecimientos de este tipo sobre castros tomados por las legiones en escenarios de las Guerras Cántabras: Amaya (Quintana, 2008, 241 ss.), Santa Marina-Monte Ornedo (Fernández Vega y Bolado, 2010) o la Espina del Gallego (Peralta, $1999 ; 2000 ; 2003 ; 2004 ; 2008$ y 2009). Esto parece indicar que se trató de una práctica sistemática por parte de las tropas romanas, muy probablemente destinada tanto al control del territorio como a una demostración de fuerza frente a los indígenas que habitaban en los alrededores de esos establecimientos fortificados. En el caso de La Loma, la presencia de esa guarnición romana en una parte del castro hace que pueda descartarse la existencia de otra similar en el interior del campamento principal, situado a escasos $180 \mathrm{~m}$ de él en línea recta. Finalmente, otro indicio que reforzaría la inexistencia de esa guarnición de tipo castellum es la propia dispersión de las monedas de Calagurris pretendidamente posteriores a 15 a. de C., ya que no se localizan concentradas en un punto concreto que pudiera identificarse con alguna construcción de tipo barracón que no hubiese sido detectada durante la intervención arqueológica, sino diseminadas por toda la superficie del establecimiento de campaña (Fig. 3). Y se reparten, además, de la misma forma que el resto de monedas, cuyas cronologías anteriores al año 25 a. de C. parecen fuera de toda discusión.

Atendiendo a lo expuesto hasta aquí, creemos que pueden hacerse algunas precisiones cronológicas acerca de las acuñaciones de la ceca de Calagurris presentes en los distintos yacimientos que forman el asedio de La Loma.

En primer lugar, las que no portan el título AVGVSTVS en sus leyendas pueden fecharse, siguiendo a Ruiz Trapero, antes del año 27 a. de C. Esta datación sería válida para la moneda $\mathrm{n}^{\circ} 23$ con leyenda NASSICA, la más antigua, y para la emisión de los duunviros Q. Antonius y L. Fabius ( ${ }^{\circ} 12,13$ y 14). Para las que sí llevan esa titulación, las de L Baebius y P. Antestio ( $n^{\circ} 15$ y 16), pensamos que debe aceptarse la datación genérica posterior a 27 a. de C. propuesta por esa misma autora. En este caso, incluso consideramos posible acotar su fecha ante quem, a tenor de su presencia en el asedio de La Loma. El hecho innegable de que éste sea un escenario bélico de las Guerras Cántabras y de que no se hayan localizado aquí monedas de Carisio acuñadas en Emerita entre 23-20 a. de C., presentes en otros contextos similares -lo que demuestra su elevado número y su rápida difusión entre las tropas destinadas en Cantabria y Asturia- nos permite proponer una fecha de acuñación para ellas entre 27 y 23 a. de C. El asedio de La Loma pudo haber tenido lugar durante las primeras campañas de las Guerras: la de conquista de Octavio y Antistio de los años 26-25 a. de C. o, como se ha propuesto recientemente (Bolado et alii, en prensa), la destinada a suprimir la rebelión de una parte de los Cántabros en 24 a. de C.

Por el contrario, aceptar las cronologías propuestas por García-Bellido y Blázquez, tanto en su versión más antigua como en la más reciente, nos obligaría a admitir, vista la inexistencia de una guarnición permanente en el campamento principal, que el asedio al oppidum de El Castro por parte de las tropas romanas, así como su toma por la fuerza y su destrucción violenta, tuvieron lugar en una fecha posterior a los años 12-11 a. de C. O lo que es lo mismo, siete u ocho años después de la supresión de la última gran rebelión de los Cántabros por Agripa y cuatro o cinco más tarde que el último episodio bélico, no localizado geográficamente, del que tenemos noticias en Hispania en el siglo I a. de C. ${ }^{10}$. Creemos que ni tan siquiera el recurso a una insurrección indígena silenciada por las fuentes, del tipo de las propuestas recientemente por Fernández Palacios (2009) en relación con la de los astures, citada hacia mediados del siglo I d. de C. en una inscripción, es asumible. De tratarse de un episodio similar, se habrían recuperado monedas acuñadas entre finales del siglo I a. de C. y mediados del I d. de $\mathrm{C}$, totalmente ausentes en el yacimiento.

En relación con la problemática datación de las acuñaciones duunvirales calagurritanas debemos hacer referencia a otro escenario de las Guerras Cántabras, cuyas monedas han sido publicadas hace unos años (Martínez Velasco, 2009) y en el que la presencia de un as de Calagurris de Q. Antonius y L. Fabius ha condicionado de manera notable su interpretación: el castellum de La Muela (Merindad de Sotoscueva, Burgos). Se trata de un pequeño establecimiento militar romano ubicado en el extremo de una península acantilada, de muy difícil acceso, que está defendido en casi todo su perímetro por cortados naturales de decenas de metros de caída, sólo interrumpidos por una empinada ladera que lo comunica con un pequeño collado; y por dos líneas paralelas de agger en el estrecho istmo de acceso a su interior. Objeto de intervenciones arqueológicas en los años 2001 y 2002, este yacimiento proporcionó todo tipo de materiales relacionados con el contingente militar que lo construyó y ocupó (Peralta, 2007): clavijas de tiendas de campaña, fíbulas en omega de origen indígena y fíbulas de tipo Aucissa, tachuelas de sandalia y restos de armamento, que incluyen varios ejemplares de pilum, una punta de pilum catapultarium, regatones y puntas de flecha. La mayor parte de las flechas habían sido disparadas

10. Dion Casio, LIV, 20, 2. 
fuera del campamento (Peralta, 2007, 499), hacia la zona de collado que constituye un segundo punto de acceso, lo que evidencia que el campamento sufrió un ataque desde ese lugar. Todo apunta a que ese ataque consiguió su objetivo, el establecimiento fue tomado al asalto y sus defensores muertos o capturados por los indígenas. A la gran concentración de materiales en un espacio muy reducido y las propias características de éstos, entre los que se encuentran varias monedas, hay que añadir la relevancia de algunos de ellos, como un par de plomos de groma. Este hecho, realmente inusual, permite ratificar esa interpretación, ya que se trata de un material sumamente valioso y que era objeto de un especial cuidado por parte de los encargados de su uso y vigilancia.

El conjunto de monedas de La Muela tiene las mismas características que han sido observadas en otros emplazamientos de las guerras contra los cántabros y los astures, con presencia de denarios republicanos de los siglos II-I a. de C., ases del valle del Ebro y de la Meseta norte de cronologías post-sertorianas, moneda augustea del sur de la Galia y acuñaciones emeritenses de Publio Carisio (Martínez Velasco, 2009, 518-521). Entre todas ellas destaca la presencia de un as de Calagurris ( $\mathrm{n}^{\circ} 1$ en la publicación) para el que en $D C P H$ se ha propuesto una fecha de acuñación de alrededor de 12-11 a. de C. Esta cronología, ya que la destrucción violenta del campamento parece fuera de toda duda, ha llevado a considerar la posibilidad de una reocupación del mismo posterior a esas fechas (Martínez Velasco, 2009, 521) como única forma de justificar la presencia de la moneda en él. Sin embargo, creemos que, como ocurre en el caso de La Loma, hay más y mejores argumentos para establecer una fecha ante quem de la moneda a partir del contexto arqueológico en el que ha sido hallada, que para obtener una datación post quem del campamento basándose en ella. De nuevo, asumir una cronología tan reciente nos obligaría, bien a aceptar la existencia de un hecho de armas en Cantabria varios años después de finalizadas las campañas militares, bien a sostener la presencia de una ocupación militar de la península de La Muela en esas fechas. Descartada la primera explicación por las razones expuestas más arriba, creemos que los argumentos contra la segunda son de peso: la propia localización del campamento, fuera de las vías principales de comunicación y/o de paso hacia el interior del territorio cántabro, y en un lugar de muy difícil acceso; la inexistencia de estructuras que indiquen la presencia de una guarnición en un momento posterior al final de las guerras, tal y como sucede en todos los yacimientos en los que sí se ha documentado esa ocupación militar, como hemos señalado anteriormente; y las propias cronologías que ofrecen el resto de las monedas recuperadas, con el ejemplar más reciente, un quinario de Carisio, fechado en los años 23-20 a. de C. Si a ello le añadimos la ausencia de argumentos de peso a la hora de establecer las cronologías de las acuñaciones de Calagurris en $\mathrm{DCPH}$, como ya hemos visto, puede afirmarse que la serie a la que pertenece ese as tiene que ser, necesariamente, anterior a los años 20-19 a. de C. Es precisamente en esos años cuando creemos que ha de fecharse el momento de la instalación, asalto y destrucción del campamento de La Muela, en el contexto de la última rebelión cántabra (Bolado et alii, en prensa). Durante esa revuelta, que sería sofocada por Agripa, las tropas romanas sufrieron serios reveses a manos de los indígenas ${ }^{11}$, alguno de los cuales pudo motivar la pérdida de las enseñas legionarias mencionadas por el propio Augusto en las Res Gestae ${ }^{12}$. Es posible que el yacimiento de La Muela sea la mejor huella arqueológica de esos sucesos que conocemos hasta la fecha.

Contamos, por tanto, con argumentos arqueológicos e históricos suficientemente sólidos para plantear una cronología temprana para las acuñaciones de Calagurris presentes en los campamentos de campaña de las Guerras Cántabras, especialmente para las emisiones duunvirales con leyenda IMP AVGVS. Su presencia en el asedio de La Loma permite suponer que al menos una parte de ellas fue acuñada con anterioridad a 24 a. de C., y que llegaron a los campamentos desde una de las cecas que aumentan su producción en estos momentos para cubrir las necesidades de moneda de las legiones que participan en las campañas de conquista. La consideración de que Calagurris actuó como ceca militar ya había sido planteada con anterioridad por García Bellido (2004, 103-104), quien advierte que comienza a desarrollar esta función, ocasionalmente en colaboración con Celsa, en torno a 27-23 a. de C.; pero que considera que en solitario únicamente lo hace a partir de 13 a. de C. con las primeras emisiones duunvirales. Todo apunta, sin embargo, a que existe una relación directa entre la ofensiva de Augusto en Hispania y la eclosión de la ceca de Calagurris, que se convierte en torno a 27 a. de C. en uno de los principales centros de suministro de moneda de bronce para el ejército. Esto sucede en un contexto de florecimiento de cecas hispanas a inicios del Principado, motivada por la escasez de acuñaciones que siguió a las Guerras Sertorianas y la acuciante necesidad de moneda de bronce que conllevó (Ripollès, 1982, 321322). Aunque parece que la puesta en circulación de nuevos ases no desapareció tras la derrota de Sertorio, como ocurrió con la de denarios, sí que disminuyó notablemente a partir del año 72 a. de C. (Ripollès, 2003, 196). Puede que la presencia en la península del ejército movilizado para la conquista de Cantabria y Asturia y la necesidad de su abastecimiento estén detrás de la activación de cecas ya existentes, como la de Calagurris, y del surgimiento de otras nuevas en los años previos a la gran ofensiva contra los pueblos del norte hispano.

11. Dion Casio, LIV, 11, 3-5.

12. Res Gestae, 29. 


\section{CONCLUSIONES}

El estudio de las colecciones numismáticas recuperadas en los campamentos romanos de campaña de las Guerras Cántabras pone de relieve la importancia que tiene el conocimiento del contexto arqueológico de los hallazgos monetarios para contribuir a su mejor interpretación y datación. Contar con materiales procedentes de yacimientos de funcionalidad conocida y cuyo arco cronológico de utilización está bastante bien acotado por la documentación permite, sobre todo, establecer unas dataciones más fiables para determinadas acuñaciones, combinando adecuadamente las dataciones post quem que ofrecen las monedas con las dataciones ante quem que ofrecen los escenarios bélicos. Un enfoque de estas características es, a nuestro entender, más fiable que el establecimiento de seriaciones a partir de criterios estilísticos o iconográficos de las representaciones presentes en el monetario.

La información que ofrecen los escasos hallazgos numismáticos de los campamentos de Castillejo y de El Alambre no es demasiado relevante, más allá de la propia constatación de que el numerario que aparece en estos yacimientos es anterior a las Guerras Cántabras y que algunos de sus rasgos son propios de contextos militares, como es el caso de la presencia de moneda partida. Sin embargo, la colección del asedio de La Loma, con más de 20 monedas, aporta datos de mucho mayor peso. En este sentido, arroja luz sobre dos cuestiones de cierto alcance en el estudio de la numismática relacionada con el ejército romano de época altoimperial en la península Ibérica: el fenómeno de la moneda partida $\mathrm{y}$, sobre todo, la función militar de algunas cecas del valle del Ebro y la cronología de sus acuñaciones.

En lo que se refiere a la moneda partida, la colección del asedio de La Loma aporta una valiosa información para cubrir el vacío existente en el periodo que separa el episodio de Andagoste ca. 44-30 a. de C. y el establecimiento de los campamentos estables del norte de la Meseta. Esta información permite corroborar que se trata de un fenómeno relacionado con el ejército y el déficit de moneda de bronce fraccionaria, que tiene continuidad durante toda la segunda mitad del siglo I a. de C. y que afecta también a los campamentos de campaña.

Sobre la cuestión de las «cecas militares» del valle del Ebro, la información que aporta este yacimiento es especialmente valiosa para conocer mejor las emisiones de Calagurris. A partir de la fecha probable del episodio bélico que tuvo lugar en La Loma, es posible proponer una cronología temprana para las acuñaciones duunvirales con leyenda IMP AVGVS del municipio calagurritano presentes en el yacimiento, posterior a 27 a. de C. y anterior a 23 a. de C.; y una estrecha relación entre el comienzo de estas emisiones y las necesidades de abastecimiento que generan las legiones que combaten en las Guerras Cántabras.

\author{
Eduardo Peralta Labrador \\ Alto de los Leones, 2, $4^{\circ}$ \\ 39010 Santander (Cantabria) \\ Edperaltas@yahoo.com \\ José Ángel Hierro Gárate \\ Grupo Tetuán-Las Canteras, $1-1^{\circ} \mathrm{B}$ \\ 39004 Santander (Cantabria) \\ jahierrogarate@gmail.com \\ Enrique Gutiérrez Cuenca \\ Eulogio Fernández Barros, 7 - $3^{\circ} \mathrm{A}$ \\ 39600 Maliaño (Cantabria) \\ egcuenca@gmail.com
}

\section{BIBLIOGRAFÍA}

ABASCAL, J.M., 2002: «La fecha de la promoción colonial de Carthago Noua y sus repercusiones edilicias», Mastia, 1, 21-44.

BELTRÁN MARTÍNEZ, A., 1984: «Numismática antigua del área de Calahorra», en Calahorra. Bimilenario de su fundación, Actas del I Symposium de historia de Calahorra, 53-67, Madrid.

BELTRÁN, A., 1949: Las monedas latinas de Cartagena, Universidad de Murcia, Murcia.

BLÁZQUEZ CERRATO, C., 1995: «Consideraciones sobre hallazgos de monedas partidas en la Península Ibérica», La moneda hispánica. Ciudad y territorio, Anejos de Archivo Español de Arqueología 14, 297-304, Madrid.

BLÁZQUEZ CERRATO, C., 2006: «Moneda partida en los campamentos romanos del norte», en M.P. GARCÍA-BELLIDO (coord.), Los campamentos romanos en Hispania (27 a.C.-192 d.C.). El abastecimiento de moneda, vol. II, Anejos de Gladius 9, 529-555, Madrid.

BLÁZQUEZ MARTÍNEZ, J. M., 1973-74: «Propaganda dinástica y culto imperial en las acuñaciones de Hispania», Actas del I Congreso Nacional de Numismática (Zaragoza), 311-319, Zaragoza.

BOLADO DEL CASTILLO, R., 2009: «Los denarios de Turiaso de la antigua Cantabria», en A. ARÉVALO GONZÁLEZ (ed.), Actas del XIII Congreso Nacional de Numismática, «Moneda y Arqueología», 325-336, Madrid-Cádiz.

BOLADO DEL CASTILLO, R. y FERNÁNDEZ VEGA, P., 2010a: «Castro de Las Rabas», Castros y castra en Cantabria, 403-428, Santander.

BOLADO DEL CASTILLO, R. y FERNÁNDEZ VEGA, P., 2010b: «Campamento de El Pedrón», Castros y castra en Cantabria, 391-396, Santander.

BOLADO DEL CASTILLO, R., GUTIERREZ CUENCA, E. y HIERRO GÁRATE, J.A., en prensa: «Las Guerras Cántabras», El pueblo cántabro en el comienzo de su historia, ADIC, Santander.

CAMINO MAYOR, J., ESTRADA GARCÍA, R. y VINIEGRA PACHECO, Y., 2001: «El campamento romano de la Vía Carisa en la Asturia Transmontana», Espacio, Tiempo y Forma. Serie I. Prehistoria y Arqueología, 14, 261-276. 
CAMINO MAYOR, J., VINIEGRA PACHECO, Y. y ESTRADA GARCÍA, R., 2005: La Carisa. Astures y romanos frente a frente, Oviedo.

CAMINO, J., ESTRADA, R. y VINIEGRA, Y., 2006: «La Carisa: un teatro del Bellum Asturicum», Arqueología Militar Romana en Hispania II: Producción y abastecimiento en el ámbito militar, 567-580, León.

CEBRIÁN SÁNCHEZ, M. A., 2008: «La fundación de la colonia Avgvsta Emerita y la nueva política monetaria», en M. P. GARCÍA-BELLIDO GARCÍA DE DIEGO, A. MOSTALAC CARRILLO y A. JIMÉNEZ DÍEZ (coords.), Del «imperivm» de Pompeyo a la «avctoritas» de Augusto. Homenaje a Michael Grant, Anejos de Archivo Español de Arqueología 47, 243249, Madrid.

CEPEDA OCAMPO, J.J., 2006a: «Los campamentos romanos de La Poza (Cantabria)», Arqueología Militar Romana en Hispania II: Producción y abastecimiento en el ámbito militar, 683-690, León.

CEPEDA OCAMPO, J.J., 2006b: «Peña Cutral (Cantabria). La vía y los campamentos romanos», Actas del Homenaje al profesor Juan María Apellániz Castroviejo, Anejos de Kobie 6, 327-338, Bilbao.

CEPEDA OCAMPO, J.J., 2007: «La Poza», El ejército romano en Hispania. Guía Arqueológica, 373-375, León.

CEPEDA OCAMPO, J.J., 2008: «Prospecciones y sondeos arqueológicos en el yacimiento de La Poza (Campoo de Enmedio). Campaña de 2003», Actuaciones Arqueológicas en Cantabria, 2000-2003, 141-144, Santander.

$D C P H=$ GARCÍA-BELLIDO, M.P. y BLÁZQUEZ CERRATO, C., 2001: Diccionario de Cecas y Pueblos Hispánicos, Madrid.

DURÁN I CAIXAL, M., 2009: Memòria del seguiment del treballs de consolidación-restauració. El Camp de les Lloses, Biblioteca del Patrimoni Cultural 6929, Barcelona

ESPINOSA RUIZ, U., 1984: Calagurris Iulia, Logroño.

FERNÁNDEZ PALACIOS, F., 2009: «¿Revueltas en la Península Ibérica en tiempos de Nerón?», Aqvila Legionis, 12, 81-99.

FERNÁNDEZ VEGA, P.A. y BOLADO DEL CASTILLO, R., 2010: "Castro y campamento de Santa Marina», Castros y castra en Cantabria, 379-386, Santander.

FRAILE LÓPEZ, M.A., 2006: Estudio geográfico de las Guerras Cántabras, Santander.

GARCIA ALONSO, M., 2002: «El campamento romano de «El Cincho» (La Población de Yuso). Un nuevo yacimiento de las Guerras Cántabras», Sautuola, VIII, 99-106.

GARCÍA ALONSO, M., 2003: «El campamento romano de El Cincho (La Población de Yuso). Resultados arqueológicos de la campaña del 2001», Sautuola, IX, 109-139.

GARCÍA ALONSO, M., 2006: «El campamento de campaña de «El Cincho» (Cantabria)», Arqueología Militar Romana en Hispania II: Producción y abastecimiento en el ámbito militar, 549-566, León.

GARCÍA ALONSO, M., 2007: «El Cincho», El ejército romano en Hispania. Guía Arqueológica, 338-341, León.
GARCÍA-BELLIDO, M.P., 2004: Las legiones hispánicas en Germania. Moneda y ejército, Anejos de Gladius 6, Madrid.

GARCÍA-BELLIDO, M.P., 2006: «El abastecimiento de moneda al ejército de Hispania en el noroeste» en M.P. GARCÍA-BELLIDO (coord.), Los campamentos romanos en Hispania (27 a.C.-192 d.C.). El abastecimiento de moneda, vol. II, Anejos de Gladius 9, 623-670, Madrid.

GIL SENDINO, F. y GARCÍA-BELLIDO, M. P., 2006: «Hallazgos monetarios en el yacimiento de La Carisa (Oviedo)» en GARCÍA-BELLIDO, M.P. (coord.), Los campamentos romanos en Hispania (27 a.C.-192 d.C.). El abastecimiento de moneda, vol. II, Anejos de Gladius 9, 447-450, Madrid.

GONZÁlEZ ÁlVAREZ, D., MENÉNDEZ BLANCO, A. y ÁLVAREZ MARTÍNEZ, V., 2008: «El campamento de Moyapan (Ayande, Asturias)», Férvedes, 5, 363-371.

GOZALBES FERNÁNDEZ DE PALENCIA, M., 2009: La ceca de Turiazu: monedas celtibéricas en la Hispania republicana, Valencia

GRANT, M., 1946: From Imperium to Auctoritas. a historical study of aes coinage in the Roman Empire, 49 B.C.A.D. 14., Cambridge.

GUTIÉRREZ CUENCA, E. y HIERRO GÁRATE, J.A., 2001: «La Guerra Cantábrica: de ficción historiográfica a realidad arqueológica», Nivel Cero, 9, 71-96.

HIERRO GÁRATE, J.A., 2010: «Estructura campamental de Salces (Salces, Campoo de Suso)», Castros y castra en Cantabria, 373-378, Santander.

MARTÍNEZ VELASCO, A., 2009: «Monedas de las Guerras Cántabras: el asedio romano de La Espina del Gallego (sierra de El Escudo, Cantabria), el campamento del Cerro de la Muela (Sotoscueva, Burgos) y el campamento de El Alambre (Valdelucio, Burgos)», Actas del XIII Congreso Nacional de Numismática, «Moneda y Arqueología», 511-523, Madrid-Cádiz.

MARTINI, R., 2008: «La reforma monetale della zecca di Roma (23 a.C.) e le emissioni bronzee Augustee di Emerita del legato P. Carisius: una regionalizzazione mancata» en M. P. GARCÍA-BELLIDO GARCÍA DE DIEGO, A. MOSTALAC CARRILLO y A. JIMÉNEZ DÍEZ (coords.), Del «imperivm» de Pompeyo a la «avctoritas» de Augusto. Homenaje a Michael Grant, Anejos de Archivo Español de Arqueología 47, 252-258, Madrid.

MORILLO CERDÁN, A. y FERNÁNDEZ OCHOA, A., 2005: «De nuevo sobre la conquista romana de Cantabria. Réplica ante una lectura tergiversada», Sautuola, XI, 161-170.

MORILLO CERDÁN, A. y GÓMEZ BARREIRO, M., 2006: "Circulación monetaria en el campamento romano de El Cincho (La Población de Yuso, Cantabria)» en M. P. GARCÍA-BELLIDO (coord.), Los campamentos romanos en Hispania (27 a.C.-192 d.C.). El abastecimiento de moneda, vol. II, Anejos de Gladius 9, 464470, Madrid.

MORILLO CERDÁN, A., PEREA YÉBENES, S. y RAMÍREZ SÁDABA, J.L., 2008: «Las Guerras Cántabras» en J.R. AJA SÁNCHEZ, M. CISNEROS CUNCHILLOS 
y J.L. RAMÍREZ SÁDABA (coords.), Los Cántabros en la Antigüedad. La Historia frente al Mito, 101-132, Santander.

NOGUERA GUILLÉN, J., 2008: «Los inicios de la conquista romana de Iberia: los campamentos de campaña del curso inferior del río Ebro», Archivo Español de Arqueología, 81, 31-48.

OCHARAN, J.A. y UNZUETA, M., 2002: «Andagoste (Cuartango, Álava). Un nuevo escenario de las guerras de conquista en el norte de Hispania», Arqueología Militar romana en Hispania, Anejos de Gladius 5, 311-325, Madrid.

PERALTA LABRADOR, E., 1997: «Arqueología de las Guerras Cántabras. Un campo de batalla en las sierras de Iguña y Toranzo», Revista de Arqueología, 198, 14-23.

PERALTA LABRADOR, E., 1998: «Espina del Gallego. El último baluarte de los cántabros», Revista de Arqueología, 212, 40-47.

PERALTA LABRADOR, E., 1999a: «Los castros cántabros y los campamentos romanos de Toranzo e Iguña. Prospecciones y sondeos (1996-1997)», Las Guerras Cántabras, 201-276, Santander.

PERALTA LABRADOR, E., 1999b: «El asedio de la Espina del Gallego (Valles de Toranzo e Iguña, Cantabria) y el problema de Aracelium», Complutum, 10, 195-212.

PERALTA LABRADOR, E., 2000: «El asedio augústeo de la Espina del Gallego. Campañas arqueológicas de 1997 a 1999», Actuaciones Arqueológicas en Cantabria 1984-1999, 363-367, Santander.

PERALTA LABRADOR, E., 2001a: «Die augusteische Belagerung von La Espina del Gallego (Kantabrien, Spanien)», Germania, 79/1, 21-42.

PERALTA LABRADOR, E., 2001b: «Los castra aestiva del Bellum Cantabricum: novedades arqueológicas», Ier Congreso Internacional de Historia Antigua, 173-182, Valladolid.

PERALTA LABRADOR, E., 2002a: «Los campamentos romanos de campaña (castra aestiva). Evidencias científicas», Nivel Cero, 10, 49-87.

PERALTA LABRADOR, E., 2002b: «Castros y campamentos romanos de las Guerras Cántabras», Los poblados fortificados del Noroeste de la Península Ibérica: Formación y desarrollo de la cultura castreña. Coloquios de arqueología en la cuenca del Navia, 225-240, Navia.

PERALTA LABRADOR, E., 2002c: «Los campamentos de las Guerras Cántabras de Iguña, Toranzo y Buelna (Cantabria)», Arqueología Militar Romana en Hispania, Anejos de Gladius 5, 327-338, Madrid.

PERALTA LABRADOR, E., 2003: Los Cántabros antes de Roma, Madrid, $2^{\text {a }}$ edición.

PERALTA LABRADOR, E., 2004a: «Cuestiones históricoarqueológicas sobre el Bellum Cantabricum y el desembarco romano en la costa cántabra», Sautuola, X, 85-130.

PERALTA LABRADOR, E., 2004b: «La conquista romana de Campoo: arqueología de las guerras cántabras», Cuadernos de Campoo, 36, 28-42.

PERALTA LABRADOR, E., 2006a: «La revisión de las Guerras Cántabras: novedades arqueológicas en el norte de Castilla», II Congreso Internacional de Arqueología Militar Romana en Hispania, 523-547, León.

PERALTA LABRADOR, E., 2006b: «El asedio de La Loma. Guerras Cántabras en la Montaña Palentina», Revista de Arqueología, 303, 24-33.

PERALTA LABRADOR, E. 2007: «Equipamiento militar romano de la conquista de la antigua Cantabria», Sautuola, XIII, 493-511.

PERALTA LABRADOR, E., 2008: «El asedio augústeo de la Espina del Gallego. Campañas arqueológicas de 2002003», Actuaciones arqueológicas en Cantabria 20002003, 153-158, Santander.

PERALTA LABRADOR, E., 2008: «La conquista romana de la Montaña Palentina: El asedio de La Loma», Colección Historia Montaña Palentina, 2, 9-36, Palencia.

PERALTA LABRADOR, E., 2009a: «Las Guerras Cántabras», en M. ALMAGRO-GORBEA (coord.), Historia Militar de España. I. Prehistoria y Antigüedad, 247265, Madrid.

PERALTA LABRADOR, E., 2009b: «El ejército romano en los siglos II-I a. C.», en M. ALMAGRO-GORBEA (coord.), Historia Militar de España. I. Prehistoria y Antigüedad, 267-281, Madrid.

PERALTA LABRADOR, E., 2011: «Campamentos romanos en Cantabria», Castillos de España, 161-162-163, 23-36.

PERALTA LABRADOR, E., SÁEZ ABAD, R. y FERNÁNDEZ IBÁÑEZ, C., 2010: «Los pila catapultaria de la Espina del Gállego. Estudio arqueológico, poliorcético y de conservación», Sautuola, XV, 277-297.

PERALTA, E., FERNÁNDEZ, F. y AYLLÓN, R., 2000: «Castros prerromanos y campamentos romanos de Iguña, Cieza y Toranzo. Prospecciones de 1996», Actuaciones Arqueológicas en Cantabria 1984-1999, 289-292, Santander.

QUINTANA LÓPEZ, J., 2008: «Amaya ¿Capital de Cantabria?», en J.R. AJA SÁNCHEZ, M. CISNEROS CUNCHILLOS y J.L. RAMÍREZ SÁDABA (coords.), Los Cántabros en la Antigüedad. La Historia frente al Mito, 229-264, Santander.

RIPOLLĖS, P.P., 1982: La circulación monetaria en la Tarraconense mediterránea, Valencia

RIPOLLÈS, P.P., 2003: «Las acuñaciones antiguas de la Península Ibérica: dependencias e innovación» en C. ALFARO ASINS, C. MARCOS ALONSO y P. OTERO MORÁN (coords.): XIII Congreso Nacional de Numismática, (Madrid, 2003), 187-208, Madrid.

RIPOLLÈS, P.P. y LLORENS, M. M., 2002: Arse-Saguntum. Historia monetaria de la ciudad y su territorio, Sagunto,

RIPOLLÈS, P. P. y ABASCAL, J. M., 2007: «Las monedas hispánicas» en M. ALMAGRO GORBEA (coord.), Monedas y medallas españolas de la Real Academia de la Historia, 23-40, Madrid.

RPC = BURNETT, A; AMANDRY, M y RIPOLLÈS, P.P., 1992: Roman Provincial Coinage. Vol. I. From the death of Caesar to the death of Vitellius (44 BC-AD 69), Londres-París. 
RUIZ TRAPERO, M., 1968: Las acuñaciones hispano-romanas de Calagurris. Su ordenación cronológica y su trascendencia histórica, Barcelona.

TORRES MARTÍNEZ, J.F., 2007: «Monte Bernorio en su entorno. Resumen de los trabajos arqueológicos efectuados en la campaña de 2004», Estudios varios de arqueología castreña. A propósito de las excavaciones de Teverga (Asturias), 77-101, Salamanca.
UNZUETA, M. y OCHARAN, J.A., 1999: «Aproximación a la conquista romana del Cantábrico Oriental: El campamento y/o campo de batalla de Andagoste (Cuartango, Álava)», Regio Cantabrorum, 125-142, Santander.

$\mathrm{CNH}=$ VILLARONGA, L., 1994: Corpus Nummum Hispaniae ante Augusti Aetatem, Madrid. 